\title{
Positive Neighborhood Norms Buffer Ethnic Diversity Effects on Neighborhood Dissatisfaction, Perceived Neighborhood Disadvantage, and Moving Intentions
}

\author{
Jasper Van Assche ${ }^{1}$, Frank Asbrock ${ }^{2}$, Arne Roets ${ }^{1}$, \& Mathias Kauff ${ }^{3}$ \\ ${ }^{1}$ Department of Developmental, Personality and Social Psychology, Ghent University \\ ${ }^{2}$ Department of Psychology, Chemnitz University of Technology \\ ${ }^{3}$ Institut für Psychologie, FernUniversität Hagen
}

Paper published in Personality and Social Psychology Bulletin

Van Assche, J., Asbrock, F., Roets, A., \& Kauff, M. (2018). Positive Neighborhood Norms

Buffer Ethnic Diversity Effects on Neighborhood Dissatisfaction, Perceived Neighborhood

Disadvantage, and Moving Intentions. Personality and Social Psychology Bulletin.

Corresponding author:

Jasper Van Assche

Department of Developmental, Personality and Social Psychology

Faculty of Psychology and Educational Sciences, Ghent University

Henri Dunantlaan 2, B-9000 Ghent (Belgium)

E-mail: Jasper.VanAssche@UGent.be

Telephone: +3292646424 / Fax: +329264 6499

Author note: The authors declare that there are no potential conflicts of interest with respect to the research, authorship, and/or publication of this article.

Word count: 9446

Running head: Positive norms buffer negative diversity effects 


\begin{abstract}
Positive neighborhood norms, such as strong local networks, are critical to people's satisfaction with, perceived disadvantage of, and intentions to stay in, their neighborhood. At the same time, local ethnic diversity is said to be detrimental for these community outcomes. Integrating both frameworks, we tested whether the negative consequences of diversity occur even when perceived social norms are positive. Study $1(N=1,760$ German adults) showed that perceptions of positive neighborhood norms buffered against the effects of perceived diversity on moving intentions via neighborhood satisfaction and perceived neighborhood disadvantage. Study $2(N=993$ Dutch adults) replicated and extended this moderated mediation model using other characteristics of diversity (i.e., objective and estimated minority proportions). Multilevel analyses again revealed consistent buffering effects of positive neighborhood norms. Our findings are discussed in light of the ongoing public and political debate concerning diversity and social and communal life.
\end{abstract}

Key words: ethnic diversity; neighborhood norms; neighborhood satisfaction; perceived neighborhood disadvantage; moving intentions 


\section{Positive Neighborhood Norms Buffer Ethnic Diversity Effects on Neighborhood Dissatisfaction, Perceived Neighborhood Disadvantage, and Moving Intentions}

Renowned political scientist Robert Putnam (1993) advanced a 'communitarian' understanding of social capital, emphasizing that positive neighborhood norms (e.g., strong local networks, mutual trust, and joint activities) greatly improve social life in a local area. At the same time, he argued that living in an ethnically diverse environment is detrimental for social cohesion (Putnam, 2007). The latter claim, also known as the 'constrict' hypothesis, has been the subject of a hot and unresolved debate among policy makers as well as academics. Putnam's former claim, however, has received far less attention in social psychological and political sciences, and, to our knowledge, research integrating both frameworks is currently lacking. The aim of the current manuscript is to investigate how ethnic diversity might affect neighborhood satisfaction, perceptions of neighborhood disadvantage, and moving intentions, while simultaneously taking into account the possible buffering role of positive neighborhood norms.

\section{Positive neighborhood norms and neighborhood life}

Positive neighborhood norms and beliefs, including friendships, reciprocity, helping behaviors, neighborhood involvement, and a sense of community, constitute some of the key dimensions of local neighborhood life (Portes, 1998). In a neighborhood setting, norms are unwritten social rules for interactions with other residents and one's behavior in public spaces. These shared norms are not always positive. In some cases, they may deliberately exclude outsiders and impose general negativity on group members (Portes, 1998). In the same vein, perceptions of negative neighborhood norms coincide with perceptions of lower 
neighborhood quality and perceptions of greater neighborhood disadvantage and deterioration. This has been called the 'dark side of social capital' (Portes \& Landolt, 1996).

However, the perception of positive norms in terms of a mutual dependency where residents live peacefully alongside each other, maintain common beliefs and trust, and cooperate successfully in case of shared interest, is an important basis of neighborhood satisfaction (e.g., Kleinhans, 2009). Moreover, positive local norms and strong social bonds are also important determinants of residents' intentions to stay in their neighborhood rather than move away (Connerly, 1986; Speare, 1974). Prior research further proposed that residents' neighborhood satisfaction can be considered a critical predictor of their mobility intentions (e.g., Lu, 1998; Morris, Crull, \& Winter, 1976). Indeed, when people feel satisfied with their neighborhood, they feel closely attached to their local area, and this strong identification with the neighborhood as a focal social category reduces their intentions to move away (Giuliani, 2003; see also Tajfel, 1982).

\section{Ethnic diversity and neighborhood life}

A second body of literature which advanced our understanding of neighborhood satisfaction, perceptions of neighborhood disadvantage, and residential mobility, is based on contextual 'neighborhood effects' studies. Originating from Schelling's theoretical work (1969), various researchers have proposed that the specific composition of a neighborhood, and more particularly, the occurrence of high concentrations of ethnic minorities, can exert a detrimental effect on residents' decisions to stay. Indeed, empirical studies have shown that individuals have a stronger wish to leave their neighborhood when they are different from their neighbors (e.g., Clark, 1991). In line with these results, studies also demonstrated that higher proportions of ethnic minorities in a neighborhood relate to a higher probability that residents wanted to leave their neighborhood (e.g., Feijten \& Van Ham, 2009; Van Ham \& 
Feijten, 2008). Literature on the 'White flight hypothesis' (Crowder, 2000) corroborates this evidence by linking the likelihood of Whites leaving their neighborhood to an increased share of minorities.

For a better understanding of the processes underlying the effect of diversity on moving intentions, it is important to investigate how diversity affects the predictors of moving intentions. Indeed, despite the bulk of research linking higher diversity to higher moving intentions, little attention has been paid to the potential association of diversity with neighborhood satisfaction and perceived neighborhood disadvantage (for a notable exception, see Laurence \& Bentley, 2015). In particular, previous research primarily focused on the consequences of diversity for intergroup relations and attitudes. On the one hand, higher diversity has been shown to relate to more contact experiences with ethnic minorities (e.g., Wagner, Van Dick, Pettigrew, \& Christ, 2003; Brune, Asbrock, \& Sibley, 2016). On the other hand, higher diversity has also been associated with more prejudice (e.g., Cernat, 2010; Quillian, 1995), more feelings of outgroup threat (Semyonov, Raijman, Tov, \& Schmidt, 2004; Taylor, 1998), and lower levels of trust (both between and within ethnic groups; Putnam, 2007).

Moreover, Putnam (2007) claimed that, in the face of diversity, individuals "pull in like a turtle" (p. 149) and withdraw from others and from social life at large. In line with this constrict claim, we assume that higher diversity would also relate to lower levels of neighborhood satisfaction and greater perception of disadvantage in that neighborhood. Some studies already focused on the perception of personal threat in one's neighborhood as a result of diversity (Chiricos, McEntire, \& Gertz, 2001; Van Assche, Roets, Dhont, \& Van Hiel, 2014, 2016). For example, Van Assche and colleagues (2014) showed that higher perceptions of diversity as well as higher actual levels of diversity, were related to higher perceptions of neighborhood threat in terms of street crime, vandalism, poverty, community demise and 
degradation, drug abuse, and unemployment. In line with these findings, Swaroop and Krysan (2001) and Hipp (2009) already reported that those perceiving more ethnic heterogeneity tend to perceive more social and physical disorder and more crime in their neighborhood, and they are less satisfied. These studies indicate that diversity has the potential to evoke lower neighborhood satisfaction and greater perceptions of neighborhood disadvantage. Such perceptions of a deteriorating neighborhood potentially increase the odds that someone wants move away (see Kearns \& Parkes, 2010).

\section{Joint effects of diversity and norms}

Ethnic diversity might thus instill greater moving intentions via lower neighborhood satisfaction and higher perceived neighborhood disadvantage, but the strength of such effects might also depend on the norms within the local environment. The seminal work of Uslaner $(2011,2012)$ suggests that segregation, rather than diversity, is the real culprit in worsened intergroup relations. Indeed, the various ethnic groups in diverse neighborhoods often have very little interpersonal interaction, and it is exactly this segregation in everyday life that inhibits the formation of close personal ties and positive local norms (see Hewstone, 2015). On the other hand, diverse neighborhoods with positive social interaction norms might offer an optimal context to foster integration and to buffer against the potential detrimental effects of diversity on neighborhood life (Aberson, 2010). Indeed, Schmid, Al Ramiah, and Hewstone (2014) already showed that the harmful effects of diversity disappear when local intergroup contact experiences are taken into account.

Furthermore, studies have shown that merely having friends who have positive intergroup contact experiences can be beneficial to intergroup relations and attitudes (i.e., the extended contact hypothesis; Wright, Aron, McLaughlin-Volpe, \& Ropp, 1997). The effectiveness of such indirect experiences is especially encouraging for it signals that mere 
knowledge that others have positive relations with minorities, can help transform attitudes. Positive social norms in a neighborhood communicate these relationship standards at a broader level and thus could produce similar effects at a more general scale. We therefore assert that perceptions of positive versus negative neighborhood norms could play a crucial role in how ethnic diversity is related to neighborhood satisfaction, to perceived neighborhood disadvantage, and in turn, to moving intentions. In particular, we hypothesize that especially for residents perceiving negative norms in their neighborhood, ethnic diversity predicts reduced neighborhood satisfaction, increased perception of neighborhood disadvantage, and heightened moving intentions. Conversely however, for those perceiving positive norms in their local environment, diversity should not have such detrimental repercussions.

To study these effects of neighborhood norms, we believe that it is warranted to carefully consider the concept of neighborhood norms (see Alaimo, Reischl, \& Allen, 2010), by looking into both general relational norms (pertaining to the general relations between residents) and intergroup relational norms (pertaining to the specific relations between immigrants and natives). ${ }^{1}$

\section{The present studies}

The current manuscript aims to fill the gap in fundamental research on several aspects of neighborhood life, i.e., neighborhood satisfaction, perceived neighborhood disadvantage, and moving intentions. Putting together various perspectives in the literature, we propose a unifying moderated mediation framework in order to advance a more complete understanding of residents' moving intentions (see Figure 1). In particular, across two studies, we examine the buffering effects of positive neighborhood norms in the relationships of diversity with neighborhood satisfaction, and with perceived neighborhood disadvantage. Furthermore, we expect that higher neighborhood satisfaction further relates to lower moving intentions and that higher perceived neighborhood disadvantage further relates to greater moving intentions. 
In sum, we hypothesize that for those who perceive the neighborhood norms to be positive, diversity will not be detrimental for neighborhood satisfaction, and will not elevate perceptions of disadvantage. Consequentially, diversity will not heighten moving intentions when neighborhood norms are positive.

To investigate each of these issues, we identify a number of considerations that deserve greater attention. First, Koopmans and Schaeffer (2015) indicated that it is important to take into account objective diversity as well as subjective diversity. For objective diversity, straightforward measures of minority proportions can be used (e.g., Semyonov et al., 2004). To assess subjective diversity, some previous studies have used a Likert scale (e.g., Van Assche et al., 2014), whereas other studies asked respondents to estimate minority proportions (e.g., Semyonov et al., 2004). However, Hooghe and De Vroome (2015) showed that individuals are quite inaccurate in estimating the actual proportion of minorities in the area they live in, and they recommend including both Likert scales and (potentially biased or exaggerated) estimations when investigating the perception of ethnic diversity. Accordingly, after we tap into only one aspect of diversity (i.e., perceived diversity) in Study 1, we consider no less than three aspects of diversity (i.e., perceived, estimated, and objective diversity) in Study 2, as a robustness check for our findings regarding the tested model.

Secondly, when examining the effects of specific variables on moving intentions, it is crucial to also control for a wide variety of individual and contextual characteristics that already have been demonstrated to significantly affect mobility decisions (Crowder, 2000). Therefore, the present study took into account twelve background and control characteristics. ${ }^{2}$ In particular, in all analyses across both studies, we included age and gender, as older individuals tend to show lower moving intentions (Long, 1988), and women tend to move more often than men (McLanahan, 1983). We further controlled for participants' education level, as this relates positively to moving intentions by expanding awareness of alternative 
residential options (Long, 1973; South \& Deane, 1993). Greater family income may increase mobility by making a wider range of alternative housing options available and by improving the ability to move in case of dissatisfaction with current residential conditions (Landale \& Guest, 1985; Newman \& Duncan, 1979). Furthermore, marital status was taken into account, as married persons tend to move less frequently than the unmarried (South \& Deane, 1993), and number of persons in the household was also controlled for, as the presence of more children tends to impede moving intentions by increasing ties to the local community and reliance on its resources and institutions (Rossi, 1955). Moreover, we controlled for home ownership and time lived in the house. Indeed, compared to renters, homeowners tend to be more tied to the community because of their substantial financial investments in their current dwelling and their greater cost and inconvenience of moving (Bach \& Smith, 1977; Landale \& Guest, 1985; Rossi, 1955; Speare, 1974). The same reasoning applies to the number of years people have been living in their house, which constitutes our eighth background

variable. In Study 2, we also considered satisfaction with the residence (i.e., the house itself) and external pressure to live in one's current house as additional individual-level control variables. Finally, in Study 2, we also were able to obtain and include objective neighborhood-level markers of security and crime as context-level control variables.

\section{Study 1}

\section{Method}

\section{Participants}

We analyzed a representative sample of German ethnic majority members $(N=1,760)$ from the 2007 wave of the Group-Focused Enmity project (Heitmeyer, 2002), specifically tapping into perceptions of neighborhood norms. The mean age of the sample was 47 years $(S D=16.02)$ and $44 \%$ were men. Twenty-eight percent of the participants had completed 
primary school, 20\% had completed lower high school, 33\% upper high school, and 18\% had a college or university degree. Income distributions are provided in Appendix A (OSF:

https://osf.io/pe2fg). The average number of persons per household was $2.46(S D=1.32)$, and $54 \%$ of the respondents were owner of their house (vs. $46 \%$ tenant or subtenant). Finally, $8 \%$ of the sample had been living in their house since birth, $61 \%$ since 5 years or more, $18 \%$ between 2 and 5 years, $10 \%$ between 6 months and 2 years, and 3\% had only been living in their house for six months or less.

\section{Measures}

\section{Perceived diversity.}

To assess perceived diversity, respondents had to indicate 'How many foreigners are there in your neighborhood?' using a 4-point rating scale ranging from 1 (very few) to 4 (a lot; $M=1.87, S D=0.80)$.

\section{Positive perceived neighborhood norms.}

To assess respondents' perceptions of the norms within their neighborhood, they were asked to evaluate two statements using 4-point Likert scales anchored by 1 (not at all true) and 4 (totally true). These items were 'People like to help each other in my neighborhood' and 'People know each other well in my neighborhood'. The items were strongly positively correlated $(r=.54, p<.001)$, yielding a scale with $M=3.17(S D=0.72)$.

\section{Neighborhood satisfaction.}

Neighborhood satisfaction was measured with two items, reading 'I feel connected with my neighborhood' and 'I feel at home in my neighborhood'. Respondents answered those items on a scale anchored by 1 (not at all true) and 4 (totally true). Both items were strongly positively correlated $(r=.51, p<.001)$, yielding a scale with $M=3.45(S D=0.62)$. 


\section{Perceived neighborhood disadvantage.}

Six indicators of perceived disadvantage in one's neighborhood were administered as follows: 'Below, a number of societal problems are listed. Please indicate for each of the problems to what extent they occur in the neighborhood where you live: Garbage and bulky waste strewn on pavements and green spaces; Drunk people; Drug addicts and drug dealers; Destroyed telephone boxes, letterboxes, dustbins, bus stops, and benches; Sprayed, smeared walls; People who threaten, rip off or beat up others'. Respondents answered all items on 4point Likert scales ranging from 1 (not a problem at all) to 4 (a big problem). An exploratory factor analysis with the principal-axis extraction method on these six indicators of perceived neighborhood disadvantage showed that, based on the eigenvalues and scree plot, all items loaded on a single factor. Cronbach's alpha was .93 , with $M=2.00(S D=0.99)$.

\section{Moving intentions.}

Two items tapped into moving intentions: 'I would prefer to live in another part of town', and 'I would rather live in another town'. Respondents answered using 4-point Likert scales ranging from 1 (not at all true) to 4 (totally true). The items showed a moderate positive relationship $(r=.25, p<.001)$. Yet, as testing them individually yielded identical effects, the items were collapsed into a single measure (with $M=1.56, S D=0.71$ ) for all analyses.

\section{Results}

\section{Preliminary Analyses}

The correlations among all study variables are presented in Table 1. Strong positive associations were found between perceived norms and neighborhood satisfaction, and strong negative relations were found between these two variables and moving intentions. An 
opposite pattern was revealed for perceived neighborhood disadvantage, which was negatively associated with perceived norms and neighborhood satisfaction, and positively related to moving intentions. Most importantly, however, were the negative associations of perceived diversity with perceived norms and neighborhood satisfaction, and the positive relations of perceived diversity with neighborhood disadvantage and moving intentions. Overall, as opposed to those perceiving low diversity, individuals who perceive their neighborhood to be highly diverse tend to perceive less positive norms and more disadvantage in their neighborhood, tend to be less satisfied with their neighborhood, and to show higher intentions to move.

Second, because respondents were nested within Kreis-districts, we investigated whether it was warranted to control for this nested structure using multilevel analyses. We estimated empty (intercept-only) models which provide insight in the variances in our mediators and outcome at the individual and contextual level. We also assessed the intraclass correlations (ICCs) to explore if there was substantial between-level variance, justifying the use of multilevel modeling. Taking into account the higher-level structure did not significantly improve the goodness-of-fit statistics for neighborhood satisfaction (i.e., change in $-2 * \log$-likelihood $\chi_{(1)}^{2}=0.27, p=.60 ;$ ICC $\left.=.00\right)$ and moving intentions $\left(\chi^{2}{ }_{(1)}=0.09, p=\right.$ .77 ; ICC $=.00$ ). However, taking into account the higher-level structure significantly improved the goodness-of-fit for disadvantage (i.e., $\chi^{2}(1)=9.50, p=.002 ; \mathrm{ICC}=.02$ ). Therefore, for specific analyses with perceived disadvantage as outcome, we applied multilevel analyses that controlled for the fact that perceptions of disadvantage are more alike within than between districts.

\section{Main Analyses}


First, we investigated whether positive perceptions of neighborhood norms moderated the association of diversity with neighborhood satisfaction, neighborhood disadvantage, and moving intentions. We conducted three regression analyses, testing the effects of diversity with norms as moderator, controlling for a number of relevant background variables (i.e., age, gender, education, household income, marital status, number of persons in the household, whether or not one owned the house, and the time lived in the house). These three interaction terms were further examined by means of simple slope analyses, testing the significance of the regression slopes at two levels of the moderator, that is, at low (i.e., $<1 S D$ below the mean) and high (i.e., > $1 S D$ above the mean) levels of perceived neighborhood norms. All predictors were centered before running the analyses (Aiken \& West, 1991). Table 2 summarizes the results of these analyses. In line with our expectations, all interaction effects were significant. Simple slope analyses showed that higher perceptions of neighborhood ethnic diversity were only associated with less neighborhood satisfaction and more perceived neighborhood disadvantage among people perceiving less positive norms in their neighborhood, and not among those perceiving positive norms in their neighborhood. Notably, although perceived diversity was still significantly positively related to higher moving intentions when perceived norms were positive, the slope was considerable weaker, indicating that the buffering effect of positive neighborhood norms also played a role with regards to moving intentions.

To test the conditional indirect effects of diversity on moving intentions via neighborhood satisfaction and disadvantage, we conducted bootstrap analyses $(N=50,000$ bootstrap samples) using Hayes' Process macro (2013) in which the associations between the predictor (i.e., perceived diversity) and the mediators (i.e., neighborhood satisfaction and perceived disadvantage) were moderated by perceived neighborhood norms (Model 7; Hayes, 2013; see Figure 2). Again, we controlled for all relevant background characteristics. The 
model tests revealed that the indirect associations of higher diversity with higher moving intentions through lower neighborhood satisfaction were only significant for those perceiving less positive norms in their neighborhood $(b=0.04$; boot S.E. $=0.02 ; \beta=0.04 ; p<.001)$, but not for those perceiving positive norms in their neighborhood $(b=0.01$; boot S.E. $=0.02 ; \beta=$ $0.01 ; p=.69)$. The indirect associations of higher diversity with higher moving intentions through higher neighborhood disadvantage were not significant for people both low $(b=0.00$; boot $S . E .=0.00 ; \beta=0.00 ; p=.25)$ and high in perceived norms $(b=0.00 ;$ boot $S . E .=0.00 ; \beta$ $=0.00 ; p=.48)$. Finally, neighborhood satisfaction, but not perceived neighborhood disadvantage, further related to less moving intentions. Hence, when taken together, only neighborhood satisfaction turned out to have unique effects on moving intentions. In line with this finding, the indirect effect via satisfaction was significantly stronger than the indirect effect via perceived disadvantage $\left(b_{\text {satisfaction- disadvantage }}=0.05 ;\right.$ boot $S . E .=0.01 ; \mathrm{CI}_{95}=[0.02$; $0.07])$.

\section{Study 2}

Study 1 showed that positive norms affect the effects of diversity perceptions, indicating that diversity perceptions increase moving intentions mostly for those who do not perceive positive norms in their neighborhood. These results as such specify how important positive norms are for the residents of a neighborhood, and especially when that neighborhood is diverse in ethnic composition. Study 2 aimed to further delineate this buffering role of positive neighborhood norms in the associations of diversity with neighborhood satisfaction, perceived neighborhood disadvantage, and moving intentions. Study 2 moved beyond Study 1 in three important ways. First, Study 2 was conducted in the Netherlands, another Western European country with a fair share of immigrants and foreigners. Secondly, in Study 2, we tapped into the effects of various aspects/measurements of diversity (i.e., perceived, estimated, and objective diversity). Third, while Study 1 tapped 
into perceptions of general norms in one's neighborhood, Study 2 tapped specifically into perceptions of intergroup norms. In sum, this study investigated the combined effects of various aspects of neighborhood diversity and norms on moving intentions via neighborhood satisfaction and disadvantage.

\section{Method}

\section{Participants}

We used a nationally stratified sample of Dutch majority members $(N=993)$ nested within neighborhoods ( $N=688$; mean number of observations per neighborhood $M=1.44$ ). This dataset was collected online in 2015 through an independent ISO 26362-certified survey company. The mean age of the sample was 50 years $(S D=16.70)$ and $52 \%$ were men. Thirtythree percent of the participants had completed primary school, 39\% had completed high school and $28 \%$ had a college or university degree. Fifty-four percent of the sample was doing paid work (see Appendix A for income distributions). On average, participants had been living in their neighborhood for 18 years $(S D=14.24)$. Sixty percent of the respondents was owner of their house, and $60 \%$ had children. Specifically, $40 \%$ of the sample was living in partnership without children, $28 \%$ was living in partnership without children, $18 \%$ was living alone, $7 \%$ was living with their parent(s) or caretaker(s), $4 \%$ was living without partner with children, and $3 \%$ was cohousing with non-relatives.

\section{Measures}

\section{Diversity.}

Perceived diversity. We used two items to assess subjectively perceived diversity in one's neighborhood (see also Van Assche et al., 2014). These items read 'How many people of immigrant origin live in your neighborhood?' and 'There is a high chance of meeting people 
of immigrant origin in my neighborhood'. Respondents answered using 7-point rating scales ranging from 1 (none / totally disagree, respectively) to 7 (a lot / totally agree, respectively). Both items were strongly positively related $(r=.71, p<.001)$, yielding a scale with $M=3.82$ $(S D=1.70)$

Estimated diversity. Another way to tap into perceptions of diversity is to assess estimates of local minority proportions (see also Semyonov et al., 2004). To measure estimated diversity, participants specified their estimated percentage of non-Western immigrants living in their neighborhood, with $M=19.00 \%(S D=19.14, M I N=0.00 \%, M A X=90.00 \%)$.

Objective diversity. To assess the actual diversity in respondents' neighborhood, we calculated the percentage of non-Western minority members within their specific neighborhood within the year of data-collection (see also Van Assche et al., 2016). We used the available data from the Dutch Central Bureau of Statistics (CBS, 2015). To get a measure of objective diversity, we calculated the number of individuals per neighborhood of nonWestern origin as a percentage of the total number of registered inhabitants $(M=12.69 \%, S D$ $=12.11, M I N=0.00 \%, M A X=76.30 \%)$.

\section{Positive perceived neighborhood norms.}

To specifically assess respondents' perceptions of the intergroup norms within their neighborhood, they were asked to evaluate two statements using 7-point Likert scales anchored by 1 (totally disagree) and 7 (totally agree). These items are 'In the neighborhood where I live, there is an atmosphere in which immigrants and natives have the will to move forward together' and 'In the neighborhood where I live, many people like to have contact with people of another ethnic group'. These items were strongly positively correlated $(r=.70$, $p<.001)$, yielding a scale with $M=3.96(S D=1.15)$.

\section{Neighborhood satisfaction.}


Neighborhood satisfaction was measured with two items, reading 'I am satisfied with my neighborhood' and 'I like to live in my neighborhood'. Respondents answered those items on a scale anchored by 1 (totally disagree) and 7 (totally agree). Both items were strongly positively correlated $(r=.87, p<.001)$, yielding a scale with $M=5.69(S D=1.39)$.

\section{Perceived neighborhood disadvantage.}

We administered three indicators of perceived disadvantage in one's neighborhood, presented as follows: 'How problematic are the following things in your neighborhood? Poor condition of the streets and houses; Crime; Unemployment'. Respondents answered 7-point Likert scales ranging from 1 (totally not problematic) to 7 (totally problematic). Cronbach's alpha was .82 , with $M=2.82(S D=1.30)$.

\section{Moving intentions.}

Finally, we administered moving intentions by three items using 7-point Likert scales anchored by 1 (totally disagree) and 7 (totally agree). An example item reads 'I think about moving to another neighborhood in my town or city in the near future'. All items were collapsed into a scale $(\alpha=.69 ; M=2.23 ; S D=1.41)$.

\section{Control variables.}

In addition to the background characteristics that relate to moving intentions administered in Study 1, we also assessed residence satisfaction and external pressure to live in one's current house as additional control variables. First, participants had to indicate on a scale ranging from 1 (totally disagree) to 7 (totally agree) to what extend they agreed with the following question: 'I am satisfied with my residence (i.e., the house or apartment itself, not the location or neighborhood)', with $M=5.73$ ( $S D=1.64)$. Next, respondents had to indicate on a scale anchored by 1 (totally voluntarily) and 7 (totally out of necessity) to what extend 
they chose their current residence voluntarily (e.g., the house and/or neighborhood are ideal) or out of necessity (e.g., cheap rent or sale price), with $M=2.20(S D=1.84)$.

Finally, we also considered two objective neighborhood-level control variables that might affect neighborhood satisfaction and particularly perceived neighborhood disadvantage and moving intentions. We retrieved the objective indicators of neighborhood livability from the data provided by the Dutch Ministry of Internal Affairs, i.e., 'Leefbaarometer' [Livability barometer] (Leidelmeijer, Marlet, Van Iersel, Van Woerkens, \& Van der Reijden, 2008). This website (www.leefbaarometer.nl) provides biennial data for 49 indicators on six dimensions that reflect quality of life. We used the data from 2015 for the dimension 'security', representing an objective indication of the safety in Dutch neighborhoods. The various indicators of the security-dimension are ruination, disruption of public policy, violent felonies, car thefts and nuisance. Every zip-code is graded with a number between -50 and 50, with zero being the national average. The mean of this scale was- $2.74(S D=26.69)$. Additionally, we were able to retrieve objective number of crimes from the Dutch Central Bureau of Statistics (CBS, 2015) and calculated the relative crime rate as a function of the number of inhabitants for every zip-code as a second indicator of objective deprivation $(M=$ $0.03 \%, S D=0.03)$.

\section{Results}

\section{Preliminary Analyses}

First, the correlations among all study variables were calculated (see Table 3). As in Study 1 , we found moderately positive associations between perceived norms and neighborhood satisfaction, and strong negative relations were found between these variables and moving intentions. Again, an opposite pattern was revealed for perceived neighborhood disadvantage. We replicated the negative associations of perceived diversity with norms and 
neighborhood satisfaction, and the positive relations of perceived diversity with neighborhood disadvantage and moving intentions found in Study 1. Similar patterns were revealed for estimated and objective diversity, two operationalizations of diversity strongly positively related to perceived diversity. Overall, compared to low neighborhood diversity, higher diversity was associated with less positive norm perceptions, more disadvantage perceptions, less neighborhood satisfaction, and higher intentions to move.

Second, we again investigated whether multilevel analyses were warranted. Taking into account the higher-level structure for neighborhood satisfaction did not significantly improve the goodness-of-fit statistics (i.e., change in $-2 * \log$-likelihood $\chi^{2}{ }_{(1)}=3.24, p=.07$; ICC $=.08)$. However, taking into account the higher-level structure significantly improved the goodness-of-fit for disadvantage (i.e., $\left.\chi_{(1)}^{2}=12.73, p<.001\right)$ and moving intentions $\left(\chi_{(1)}^{2}=\right.$ $5.58, p=.02)$. In the same vein, the ICCs of .19 and .10 indicated that there was substantial between-level variance in perceptions of neighborhood disadvantage and moving intentions, respectively. Therefore, for specific analyses with perceived disadvantage and moving intentions as individual-level outcome variables, we applied multilevel analyses. ${ }^{3}$

\section{Main Analyses}

First, we investigated whether positive perceptions of neighborhood norms moderated the association of diversity with neighborhood satisfaction, perceived neighborhood disadvantage, and moving intentions. We conducted nine regression analyses, testing the effects of the three diversity facets, with positive perceptions of neighborhood norms as moderator, controlling for relevant background variables (i.e., age, gender, education, household income, marital status, number of persons in the household, whether or not one owned the house, the time lived in the house, residence satisfaction, external pressure to live in one's current house, and objective neighborhood-level markers of security and crime). 
These nine interaction terms were further examined by means of simple slope analyses. All predictors were centered before running the analyses (Aiken \& West, 1991). Table 4 summarizes the results of these analyses. All interaction effects were significant, except for the interactions between estimated diversity and norms, and between objective diversity and norms, on moving intentions. Nonetheless, a closer look at the simple slopes revealed a very straightforward and consistent story: higher perceptions, higher estimates, and higher actual levels of neighborhood ethnic diversity were especially associated with lower neighborhood satisfaction, higher perceived neighborhood disadvantage, and higher moving intentions among people perceiving less positive norms in their neighborhood, as opposed to those perceiving positive norms in their neighborhood. Notably, when perceived norms were positive, perceived diversity was even not significantly related to neighborhood satisfaction, and objective diversity was not related to neighborhood satisfaction and moving intentions. ${ }^{4}$

Second, to test the conditional indirect effects of diversity on moving intentions via neighborhood satisfaction and disadvantage, we applied a similar strategy as in Study 1 by conducting bootstrap analyses ( $N=50,000$ bootstrap samples) in which the associations between the predictor (i.e., perceived, estimated, or objective diversity) and the mediators (i.e., neighborhood satisfaction and disadvantage) were moderated by perceived norms (see Figure 3; see Figure A in Appendix B for the similar results with personal intergroup norms). Again, we controlled for all relevant control variables. The model tests revealed that the indirect associations of higher diversity with higher moving intentions through lower neighborhood satisfaction were more pronounced among those perceiving less positive norms in their neighborhood $(b=0.10$; boot S.E. $=0.02 ; \beta=0.12 ; p<.001$ for perceived diversity; $b$ $=0.97$; boot S.E. $=0.16 ; \beta=0.13 ; p<.001$ for estimated diversity; and $b=1.28$; boot S.E. $=$ $0.29 ; \beta=0.11 ; p<.001$ for objective diversity), compared to those perceiving strong positive norms $(b=0.02$; boot S.E. $=0.01 ; \beta=0.02 ; p=.02$ for perceived diversity; $b=0.31$; boot 
S.E. $=0.12 ; \beta=0.04 ; p<.001$ for estimated diversity; and $b=-0.11 ;$ boot S.E. $=0.21 ; \beta=-$ $0.01 ; p=.81$ for objective diversity; see Figure 3a, 3b, and 3c, respectively). The indirect associations of higher diversity with higher moving intentions through higher perceived neighborhood disadvantage also tended to be stronger among people low $(b=0.03$; boot S.E. $=0.02 ; \beta=0.04 ; p=.01$ for perceived diversity; $b=0.33$; boot $S . E .=0.14 ; \beta=0.04 ; p=.009$ for estimated diversity; and $b=0.37$; boot S.E. $=0.15 ; \beta=0.03 ; p=.002$ for objective diversity) versus high in perceived positive norms $(b=0.02$; boot S.E. $=0.01 ; \beta=0.02 ; p=$ .01 for perceived diversity; $b=0.21$. boot $S . E .=0.09 ; \beta=0.03 ; p=.01$ for estimated diversity; and $b=0.18$; boot S.E. $=0.10 ; \beta=0.02 ; p=.005$ for objective diversity; see Figure $3 \mathrm{a}, 3 \mathrm{~b}$, and $3 \mathrm{c}$, respectively).

Finally, as expected, neighborhood satisfaction further related to less moving intentions, and perceived neighborhood disadvantage further related to more moving intentions (albeit to a lesser extent). In line with these findings, the indirect effect via satisfaction was significantly stronger than the indirect effect via disadvantage $\left(b_{\text {satisfaction- }}\right.$ disadvantage $=0.04 ;$ boot $S . E .=0.02 ; \mathrm{CI}_{95}=[0.00 ; 0.08]$ for perceived diversity; $b_{\text {satisfaction- }}$ disadvantage $=0.44 ;$ boot $S . E .=0.20 ; \mathrm{CI}_{95}=[0.05 ; 0.84]$ for estimated diversity $)$, but not for objective diversity $\left(b_{\text {satisfaction- disadvantage }}=0.31\right.$; boot S.E. $\left.=0.23 ; \mathrm{CI}_{95}=[-0.11 ; 0.79]\right)$.

In sum, the basic buffering pattern we found in Study 1 was replicated in Study 2 using another operationalization of norms (i.e., perceptions of specific intergroup norms) and using various diversity indices (i.e., perceived, estimated, and objective diversity). This is strong support for the claim that neighborhood norms are essential and both the perception of and the belief in a positive atmosphere in the neighborhood decreases negative effects of diversity.

\section{Discussion}


Positive norms are commonly regarded as part of the "social glue" that holds communities together, with a range of positive outcomes for local neighborhood life (Putnam, 1993). Meanwhile, ethnically diverse neighborhoods impose a challenge to social cohesion and local neighborhood life (Putnam, 2007). The present set of studies shed new light on these frameworks by investigating the additive and interactive roles of norms and diversity, establishing consistent buffering effects of positive neighborhood norms on the relationship between neighborhood diversity and higher moving intentions via (lower) neighborhood satisfaction and to a lesser extent via (higher) perceived neighborhood disadvantage. In particular, a closer inspection of the slopes for individuals low versus high in positive norms specified that various facets of diversity are detrimental for individuals' satisfaction with their neighborhood life, but especially or even exclusively among individuals who perceive less positive norms in their local area. Thus, positive neighborhood norms maintain social cohesion in a neighborhood, even under a potential threat like high diversity.

\section{Moving out of the hood: A complex story}

What makes people leave or stay in a neighborhood? Our findings consistently show that norms seem to play an essential role in various aspects of social life in a neighborhood. Indeed, individuals' intentions to move greatly depend on their levels of satisfaction with their neighborhood, which in turn depend on how diverse one's neighborhood is and if one perceives positive norms such as strong local networks and neighborhood involvement. As such, we integrated the literature on positive neighborhood norms as the 'bright side of social capital' (cf. Portes \& Landolt, 1996) and the literature on ethnic diversity as the 'enemy of local social life' (see Clark, 1991; Putnam, 2007). In accordance with Van Ham and Feijten (2008) as well as Feijten and Van Ham (2009), our results show that diversity across the board is associated with higher moving intentions. However, the story is not that simple and straightforward, as a complex interplay between diversity and norms seems to determine 
one's moving intentions through one's satisfaction with the neighborhood, and to a lesser extent through one's perceptions of disadvantage and deterioration within the local community. More specifically, positive norms buffer against negative diversity effects, and diversity is not harmful to neighborhood attitudes when norms are positive.

Moreover, this buffering effect was found consistently a) across two large samples from two different countries (i.e. Germany and the Netherlands), b) across various facets of diversity (cf. Koopmans \& Schaeffer, 2015), namely for perceived, estimated, and objective diversity, and c) across various facets of social norms (cf. Alaimo et al., 2010), namely for perceptions of general local norms and perceptions of local intergroup norms. In sum, higher perceptions, higher estimates, and higher actual levels of neighborhood ethnic diversity appear to instigate perceptions of neighborhood disadvantage and especially neighborhood dissatisfaction in individuals who do not perceive positive local norms, but not in individuals who do consider the norms in the neighborhood to be positive. As such, dependent on their perceptions of the local neighborhood, some individuals wish to move away in the face of diversity while others do not.

\section{Promoting positive hood norms: A challenging story}

An effective way to encourage positive general norms is by creating shared neighborhood goals and a mutual dependency where residents have the opportunity to get to know one another, cooperate successfully and in general learn to get along well. Such small and non-intrusive, organized events have been shown to effectively boost residents' local bonds and satisfaction with their neighborhood (e.g., Kleinhans, 2009). An effective way to endorse positive intergroup norms is by stimulating intergroup contact between local immigrants and 'natives'. Multi-ethnic contexts effectively provide opportunities for contact between ethnic groups (see Frølund Thomsen, 2012; Huijts, Kraaykamp, \& Scheepers, 2014; Schlueter \& Wagner, 2008; Stein, Post, \& Rinden, 2000). Moreover, intergroup contact has 
been shown to effectively improve various forms of intergroup attitudes and trust (Hewstone \& Swart, 2011; Hewstone et al., 2014; Pettigrew \& Tropp, 2006; Pettigrew, Tropp, Wagner, \& Christ, 2011), and hence to countervail negative effects of diversity on trust (Schmid et al., 2014). Contact between members of different ethnic groups should thus be central to policy makers aiming to manage the local intergroup atmosphere, as such tackling inhabitants' potential intentions to move to another place.

Furthermore, our interaction approach of simultaneously taking into account psychological and socio-structural variables in the prediction of social phenomena speaks directly to Pettigrew's $(1991,2008)$ calls for an integrative 'contextual social psychology'. By considering the interplay between norms and diversity in various processes related to local neighborhood life, our research extends previous diversity studies that applied a similar framework to the field of intergroup relations. Indeed, following Putnam's 'hunkering down' article (2007), research has accumulated evidence for conditional diversity effects on social cohesion of communities (e.g., Brune et al., 2016; Kauff, Asbrock, Thörner, \& Wagner, 2013; Van Assche et al., 2014, 2016). Our findings extend this interaction perspective by demonstrating conditional diversity effects on neighborhood satisfaction, perceived neighborhood disadvantage, and moving intentions, even when controlling for other relevant influences.

\section{Merits, limitations and avenues for future research}

The first asset of the present set of studies pertains to the inclusion of multiple well justified control variables (cf. Bernerth \& Aguinis, 2016), such as marital status and neighborhood-level crime rates. We also included multiple outcomes, such as neighborhood satisfaction, perceived neighborhood disadvantage, and actual intentions to move away, which were not included in previous diversity studies. A second merit lies in the inclusion of several 
aspects of both diversity and norms. First, the similarity in findings for perceived and objective measures of diversity indicates that effects found with the subjective measures are robust and could not merely be attributed to biased or extreme responding. Second, we were able to replicate the buffering effect of positive norms across various samples and various measures, as such attesting to its robustness and offering strong evidence for policy makers aiming implement specific interventions. Indeed, local neighborhood workers and volunteers need not be pessimistic: diversity is not destructive for social life per se, since its potentially harmful effects on neighborhood satisfaction and perceived disadvantage can effectively be countered by promoting positive neighborhood norms.

The present research provides an extended perspective on how social norms may shape the relationship of ethnic diversity in one's neighborhood with one's feelings of satisfaction and disadvantage in that neighborhood, and one's intentions to move. To understand the diversity - neighborhood attitudes associations, it is vital to look at interactions, as diversity can have divergent effects dependent on individual moderators such as perceived neighborhood norms. Although this study provides new insights into the additive and interactive effects of norms and diversity in shaping individuals' moving intentions via satisfaction and perceived disadvantage, it also raises new questions.

First, due to the cross-sectional nature of our datasets, we cannot draw firm conclusions with regards to causality of any effects. For instance, longitudinal designs looking at neighborhood attitudes over time could test whether changes in local diversity relate to changes in residents' satisfaction over time, or whether satisfied residents proactively choose homogenous neighborhoods to live in. Ideally, further (field-)experimental work could additionally study consequences of experimental variations in perceptions of neighborhood diversity (Enos, 2014). 
Second, in the present study, we either ran a secondary analysis of an already existing dataset (Study 1), or we chose a broad approach with respondents covering the entire country (Study 2), which resulted in samples where the majority of respondents had a unique neighborhood zip-code. Yet, to further corroborate the norm-dependent relationship between diversity and neighborhood attitudes (and the behavioral consequences thereof), future studies could collect clearly nested data with more observations per contextual unit. Such studies could purposefully select broader units of analysis (e.g., cities or districts) in order to examine if diversity and norms play a similar role at a larger contextual level. Nonetheless, previous studies indicated that diversity in the local neighborhood makes a stronger impression on individuals (Schaeffer, 2014), as the neighborhood is the direct geographical environment in which people spend most of their social time (Tolsma van der Meer, \& Gesthuizen, 2009). As such, the current manuscript analyzed the joint effects of norms and diversity at the lowest (and potentially most relevant) level of analysis. Yet, future studies incorporating various contextual levels are needed to substantiate our findings in broader environments (cf., Van Assche, Roets, De keersmaecker, \& Van Hiel, 2016).

As self-report methods tapping into perceptions of local norms have certain limitations, future studies could also help our understanding of local neighborhood life by using additional methodological techniques, such as social network analyses (see Wölfer \& Hewstone, 2017). Such dynamic analyses could generate alternative, network-based "norm parameters" that account for the full complexity of underlying (direct and indirect) ties between residents in a local neighborhood (Wölfer et al., 2017).

Finally, our results add a crucial piece of the puzzle that goes beyond previous research unraveling the complex and multifaceted diversity effects. By including relevant control variables, and simultaneously studying the moderating role of norms and the mediating role of satisfaction and perceived disadvantage in the effects of diversity on moving 
intentions, this study avoided 'the Single Factor Fallacy' (Pettigrew \& Hewstone, 2017). Instead of ignoring critical influences, we included a wide variety of critical predictive and control variables into one coherent and comprehensive model. Additionally, we applied mediation-moderation and multilevel analysis as suggested by Pettigrew and Hewstone (2017). Nonetheless, these authors also pointed out that multiple item measures are more reliable and yield larger effect sizes. Building on secondary data, we were unable to do so for all variables. Also, we did not consider closely related constructs (e.g. trust, cohesion, intergroup contact, or intergroup action tendencies) that are relevant in this line of research, as outcomes or mediators predicting moving intentions. Hence, this research should be regarded as an initial step and will hopefully encourage future research to further develop this interesting theoretical framework.

\section{Conclusion}

The current set of two studies carefully delineated a model showing the complex interplay between neighborhood norms and ethnic diversity in neighborhood satisfaction, perceived neighborhood disadvantage, and moving intentions, concluding that positive norms can buffer against negative diversity effects. 


\section{Notes}

${ }^{[1]}$ Within the category of intergroup norms, we further distinguished between perceived norms (reflecting views on how intergroup relations in one's neighborhood are) and personal norms (reflecting views on the value of diversity). Indeed, while diversity effects might depend upon people's perceptions of general and intergroup norms in their neighborhood, they might similarly depend upon people's personal beliefs about diversity, multiculturalism, and intergroup relations at large. In a series of additional analyses (see Appendix B), we considered personal intergroup norms (i.e., diversity beliefs) as a moderator, as such aiming to replicate the buffering effects of intergroup norm perceptions for general intergroup beliefs.

${ }^{\text {[2] }}$ Analyses that do not include the control variables yielded virtually identical results and are available upon request with the first author.

${ }^{[3]}$ According to Maas and Hox (2005), multilevel analyses can legitimately be performed with a low number of respondents per contextual unit, providing that a) model fits increase significantly when taking into account the nested structure in the data, and b) ICCs are sufficiently large. When considering perceived neighborhood disadvantage (in both studies) and moving intentions (in Study 2) as outcomes, these two conditions were met.

${ }^{\text {[4] }}$ Through a similar procedure, we ran nine regression analyses with positive personal intergroup norms as moderator. As portrayed in Table B in Appendix B, all interaction effects were significant, and the simple slopes analyses again indicated that higher diversity (in all its forms) was most strongly associated with lower neighborhood satisfaction, greater perceived neighborhood disadvantage, and greater moving intentions among people holding less positive intergroup norms, as opposed to those holding strong positive intergroup norms that value diversity and multiculturalism in a neighborhood. Hence, the buffering effect of norms 
not only applied to perceptions of one's specific neighborhood, but also to one's personal norms regarding the value of intergroup relations in general. 


\section{References}

Aberson, C. L. (2010). Diversity experiences and intergroup attitudes. In R. J. Crisp (Ed.), The Psychology of Social and Cultural Diversity (pp. 171-189).

Aiken, L. S., West, S. G., \& Reno, R. R. (1991). Multiple regression: Testing and interpreting interactions. Sage.

Alaimo, K., Reischl, T. M., \& Allen, J. O. (2010). Community gardening, neighborhood meetings, and social capital. Journal of Community Psychology, 38(4), 497514.

Bach, R. L. \& Smith, J. (1977). Community satisfaction, expectations of moving, and migration. Demography, 14, 147-167.

Bernerth, J. B., \& Aguinis, H. (2016). A critical review and best-practice recommendations for control variable usage. Personnel Psychology, 69(1), 229-283.

Brune, A., Asbrock, F., \& Sibley, C. G. (2016). Meet Your Neighbours. Authoritarians Engage in Intergroup Contact When They have the Opportunity. Journal of Community \& Applied Social Psychology, 26(6), 567-580.

CBS (Centraal Bureau voor de Statistiek). (2015). Jaarrapport Integratie 2015. [Annual Report on Integration 2015]. Dutch Central Bureau of Statistics, Den Haag. Available from: <http://statline.cbs.nl> (last access 16.02.17).

Cernat, V. (2010). Intergroup contact in Romania: When minority size is positively related to intergroup conflict. Journal of Community \& Applied Social Psychology, 20(1), 1529. 
Chiricos, T., McEntire, R., \& Gertz, M. (2001). Perceived racial and ethnic composition of neighborhood and perceived risk of crime. Social Problems, 48(3), 322-340.

Christ, O., Schmid, K., Lolliot, S., Swart, H., Stolle, D., Tausch, N., Al Ramiah, A., Wagner, U., Vertovec, S., \& Hewstone, M. (2014). Contextual effect of positive intergroup contact on outgroup prejudice. Proceedings of the National Academy of Sciences, 111(11), 3996-4000.

Clark, W. A. (1991). Residential preferences and neighborhood racial segregation: A test of the Schelling segregation model. Demography, 28(1), 1-19.

Cole, D. A., \& Maxwell, S. E. (2003). Testing mediational models with longitudinal data: questions and tips in the use of structural equation modeling. Journal of Abnormal Psychology, 112(4), 558-577.

Connerly, C. E. (1986). The impact of neighborhood social relations on prospective mobility, Social Science Quarterly 67, 186-194.

Crowder, K. (2000). The racial context of white mobility: An individual-level assessment of the white flight hypothesis. Social Science Research, 29(2), 223-257.

Enos, R. D. (2014). Causal effect of intergroup contact on exclusionary attitudes. PNAS, 111(10), 3699- 3704.

Feijten, P., \& Van Ham, M. (2009). Neighbourhood change... reason to leave?. Urban studies, 46(10), 2103-2122.

Frølund Thomsen, J. P. (2012). How does intergroup contact generate ethnic tolerance? The contact hypothesis in a Scandinavian context. Scandinavian Political Studies, 35(2), 159-178. 
Giuliani, M. V. (2003). Theory of attachment and place attachment. In M. Bonnes, T. Lee, \& M. Bonaiuto (Eds.), Psychological theories for environmental issues (pp. 137-170). Ashgate, Hants.

Hayes, A. F. (2013). Introduction to mediation, moderation, and conditional process analysis: A regression-based approach. Guilford Press.

Heitmeyer, W. (2002). Gruppenbezogene Menschenfeindlichkeit: Die Theoretische Konzeption und Erste Empirische Ergebnisse [Group-Focused Emnity: Theoretical Conception and First Empirical Results], in Heitmeyer, W. Deutsche Zustände I [German States 1], pp. 15-34. Frankfurt: Edition Suhrkamp

Hewstone, M., \& Swart, H. (2011). Fifty-odd years of inter-group contact: From hypothesis to integrated theory. British Journal of Social Psychology, 50(3), 374-386.

Hewstone, M., Lolliot, S., Swart, H., Myers, E., Voci, A., Al Ramiah, A., \& Cairns, E. (2014). Intergroup contact and intergroup conflict. Peace and Conflict: Journal of Peace Psychology, 20(1), 39-53.

Hipp, J. R. (2009). Specifying the determinants of neighborhood satisfaction: A robust assessment in 24 metropolitan areas. Social Forces, 88(1), 395-424.

Hooghe, M., \& De Vroome, T. (2015). The perception of ethnic diversity and antiimmigrant sentiments: A multilevel analysis of local communities in Belgium. Ethnic and Racial Studies, 38(1), 38-56.

Huijts, T., Kraaykamp, G., \& Scheepers, P. (2014). Ethnic diversity and informal intra-and inter-ethnic contacts with neighbours in The Netherlands: A comparison of natives and ethnic minorities. Acta Sociologica, 57(1), 41-57. 
Kauff, M., Asbrock, F., Thörner, S., \& Wagner, U. (2013). Side Effects of Multiculturalism The Interaction Effect of a Multicultural Ideology and Authoritarianism on Prejudice and Diversity Beliefs. Personality and Social Psychology Bulletin, 39, 305-320.

Kearns, A., \& Parkes, A. (2003). Living in and leaving poor neighbourhood conditions in England. Housing Studies, 18(6), 827-851.

Kleinhans, R. (2009). Does social capital affect residents' propensity to move from restructured neighbourhoods?. Housing Studies, 24(5), 629-651.

Koopmans, R., \& Schaeffer, M. (2015). Relational diversity and neighbourhood cohesion. Unpacking variety, balance and in-group size. Social Science Research, 53, 162176.

Landale, N. S. \& Guest, A. M. (1985). Constraints, satisfaction and residential mobility: Speare's model reconsidered. Demography, 22, 199-222.

Laurence, J., \& Bentley, L. (2015). Does ethnic diversity have a negative effect on attitudes towards the community? A longitudinal analysis of the causal claims within the ethnic diversity and social cohesion debate. European Sociological Review, 32(1), 54-67.

Leidelmeijer, K., G., Marlet, J., Van Iersel, C., Van Woerkens, \& Van der Reijden, H. (2008). De Leefbaarometer: Leefbaarheid in Nederlandse Wijken en Buurten Gemeten en Vergeleken. [The Livability Barometer: Quality of Life in Dutch Districts and Neighbourhoods Measured and Compared.]. Amsterdam, Dutch Ministry of Internal Affairs, The Netherlands: RIGO and Atlas voor gemeenten.

Long, L. H. (1973). Migration differentials by education and occupation: Trends and variations. Demography, 10(2), 243-258. 
Long, L. (1988). Migration and residential mobility in the United States. Russell Sage Foundation.

Lu, M. (1998). Analyzing migration decisionmaking: relationships between residential satisfaction, mobility intentions, and moving behavior. Environment and Planning A, 30(8), 1473-1495.

Maas, C. J., \& Hox, J. J. (2005). Sufficient sample sizes for multilevel modeling. Methodology, 1, 86-92.

McLanahan, S. S. (1983). Family structure and stress: A longitudinal comparison of two-parent and female-headed families. Journal of Marriage and the Family, 347-357.

Morris, E. W., Crull, S. R., \& Winter, M. (1976). Housing norms, housing satisfaction and the propensity to move. Journal of Marriage and the Family, 309-320.

Newman, S. J. \& Duncan, G. J. (1979). Residential problems, dissatisfaction, and mobility. Journal of the American Planning Association, 45, 154-166.

Pettigrew, T. F. (1991). Normative Theory in Intergroup Relations: Explaining Bo th Harmony an d Conflict. Psychology and Developing Societies, 3(1), 3-16.

Pettigrew, T. F. (2008). Future directions for intergroup contact theory and research. International Journal of Intercultural Relations, 32(3), 187-199.

Pettigrew, T. F., \& Hewstone, M. (2017). The Single Factor Fallacy: Implications of Missing Critical Variables from an Analysis of Intergroup Contact Theory. Social Issues and Policy Review, 11(1), 8-37.

Pettigrew, T. F., \& Tropp, L. R. (2006). A meta-analytic test of intergroup contact theory. Journal of Personality and Social Psychology, 90(5), 751-783. 
Pettigrew, T. F., Tropp, L. R., Wagner, U., \& Christ, O. (2011). Recent advances in intergroup contact theory. International Journal of Intercultural Relations, 35(3), 271-280.

Portes, A. (1998). Social capital: its origins and applications in modern sociology. Annual Review of Sociology, 24, 1-24.

Portes, A. \& Landolt, P. (1996). The Downside of Social Capital. American Prospect, $26,18-21$.

Putnam, R. D. (1993). The prosperous community. The American Prospect, 4(13), 3542.

Putnam, R. D. (2007). E pluribus unum: Diversity and community in the twenty-first century the 2006 Johan Skytte Prize Lecture. Scandinavian Political Studies, 30(2), 137-174.

Quillian, L. (1995). Prejudice as a response to perceived group threat: Population composition and anti-immigrant and racial prejudice in Europe. American Sociological review, 586-611.

Rossi, P. H. (1955). Why families move: A study in the social psychology of urban residential mobility. Glencoe, IL: Free Press.

Schaeffer, M. (2014). Ethnic diversity and social cohesion: Immigration, ethnic fractionalization and potentials for civic action. Ashgate Publishing, Ltd..

Schelling, T. C. (1969). Models of segregation. The American Economic Review, 59(2), 488-493.

Schlueter, E., \& Wagner, U. (2008). Regional differences matter: Examining the dual influence of the regional size of the immigrant population on derogation of immigrants in Europe. International Journal of Comparative Sociology, 49(2-3), 153-173. 
Schmid, K., Al Ramiah, A. \& Hewstone, M. (2014). Neighborhood ethnic diversity and trust: The role of intergroup contact and perceived threat. Psychological Science, 25(3), 665-674.

Semyonov, M., Raijman, R., Tov, A. Y., \& Schmidt, P. (2004). Population size, perceived threat, and exclusion: A multiple-indicators analysis of attitudes toward foreigners in Germany. Social Science Research, 33(4), 681-701.

South, S. J., \& Deane, G. D. (1993). Race and residential mobility: Individual determinants and structural constraints. Social Forces, 147-167.

Speare, A. (1974). Residential satisfaction as an intervening variable in residential mobility. Demography, 11, 173-188.

Stein, R. M., Post, S. S., \& Rinden, A. L. (2000). Reconciling context and contact effects on racial attitudes. Political Research Quarterly, 53(2), 285-303.

Swaroop, S., \& Krysan, M. (2011). The determinants of neighborhood satisfaction: Racial proxy revisited. Demography, 48(3), 1203-1229.

Tajfel, H. (Ed.). (1982). Social identity and intergroup relations. Cambridge University Press.

Taylor, M. C. (1998). How white attitudes vary with the racial composition of local populations: Numbers count. American Sociological Review, 512-535.

Tolsma, J., Kraaykamp, G.L.M., Graaf, P.M. de, Kalmijn, M., \& Monden, C.M. (2014): Netherlands Longitudinal Lifecourse Study - NELLS Panel Wave 12009 and Wave 2 2013 - version 1.1. DANS. 
Tolsma, J., van der Meer, T., \& Gesthuizen, M. (2009). The impact of neighbourhood and municipality characteristics on social cohesion in the Netherlands. Acta Politica, 44(3), 286-313.

Uslaner, E. M. (2011). Trust, diversity, and segregation in the United States and the United Kingdom. Comparative Sociology, 10(2), 221-247.

Uslaner, E. M. (2012). Segregation and mistrust: Diversity, isolation, and social cohesion. Cambridge University Press.

Van Assche, J., Roets, A., De keersmaecker, J. \& Van Hiel, A. (in press). The mobilizing effect of right-wing ideological climates: Cross-level interaction effects on different types of outgroup attitudes. Political Psychology.

Van Assche, J., Roets, A., Dhont, K., \& Van Hiel, A. (2014). Diversity and out-group attitudes in the Netherlands: The role of authoritarianism and social threat in the neighbourhood. Journal of Ethnic and Migration Studies, 40(9), 1414-1430.

Van Assche, J., Roets, A., Dhont, K., \& Van Hiel, A. (2016). The association between actual and perceived ethnic diversity: The moderating role of authoritarianism and implications for outgroup threat, anxiety, and mistrust. European Journal of Social Psychology, 46(7), 807-817.

Van Ham, M., \& Feijten, P. (2008). Who wants to leave the neighbourhood? The effect of being different from the neighbourhood population on wishes to move. Environment and Planning A, 40(5), 1151-1170.

Wagner, U., Van Dick, R., Pettigrew, T. F., \& Christ, O. (2003). Ethnic prejudice in East and West Germany: The explanatory power of intergroup contact. Group Processes \& Intergroup Relations, 6(1), 22-36. 
Wölfer, R., \& Hewstone, M. (2017). Beyond the dyadic perspective: 10 Reasons for using social network analysis in intergroup contact research. British Journal of Social Psychology.

Wölfer, R., Jaspers, E., Blaylock, D., Wigoder, C., Hughes, J., \& Hewstone, M. (2017). Studying Positive and Negative Direct and Extended Contact: Complementing SelfReports With Social Network Analysis. Personality and Social Psychology Bulletin.

Wright, S. C., Aron, A., McLaughlin-Volpe, T., \& Ropp, S. A. (1997). The extended contact effect: Knowledge of cross-group friendships and prejudice. Journal of Personality and Social Psychology, 73(1), 73-90. 


\section{Tables}

Table 1. Correlations among Study Variables in Study 1

\begin{tabular}{llllll}
\hline \multicolumn{2}{l}{ Measure } & 1 & 2 & 3 & 4 \\
1. & Perceived diversity & - & & & \\
2. & Perceived norms & $-.28 * * *$ & - & & \\
3. & Neighborhood satisfaction & $-.16^{* * *}$ & $.34 * * *$ & - & \\
4. & Neighborhood disadvantage & $.15^{* * *}$ & $-.08 * * *$ & $-.08 * * *$ & - \\
5. & Moving intentions & $.20 * * *$ & $-.23 * * *$ & $-.51 * * *$ & $.08 * * *$ \\
\hline
\end{tabular}

Note: $*: p<.05 ; * *: p<.01 ; * * *: p<.001$ 
Table 2. Standardized and Unstandardized Estimates ( $\mathrm{CI}_{95}$ in Brackets) of Regression Analyses in Study 1 Examining the Role of Perceived Norms in Neighborhood Satisfaction, Perceived Neighborhood Disadvantage, and Moving Intentions (Controlling for Background

Characteristics)

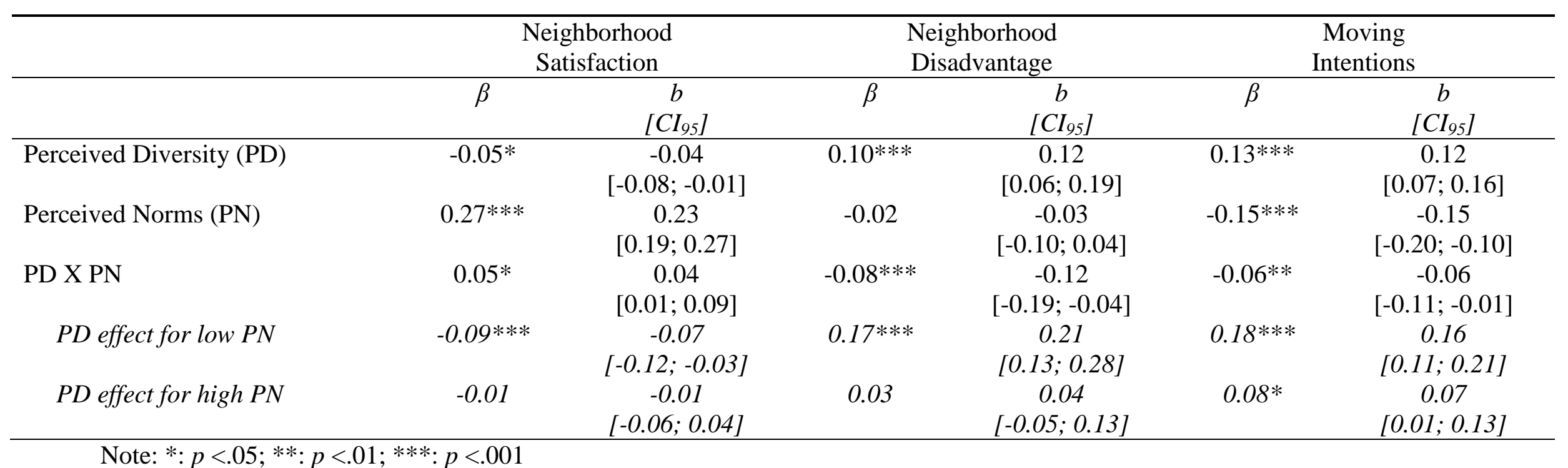


Table 3. Correlations among Study Variables in Study 2

\begin{tabular}{|c|c|c|c|c|c|c|c|}
\hline \multicolumn{2}{|c|}{ Measure } & 1 & 2 & 3 & 4 & 5 & 6 \\
\hline 1. & Perceived diversity & - & & & & & \\
\hline 2. & Estimated diversity & $.69 * * *$ & - & & & & \\
\hline 3. & Objective diversity & $.53 * * *$ & $.60 * * *$ & - & & & \\
\hline 4. & Perceived norms & $-.07 *$ & $-.08 *$ & .01 & - & & \\
\hline 5. & Neighborhood satisfaction & $-.32 * * *$ & $-.38 * * *$ & $-.22 * * *$ & $.13 * * *$ & - & \\
\hline 6. & Neighborhood disadvantage & $.49 * * *$ & $.51 * * *$ & $.36 * * *$ & $-.16^{* * *}$ & $-.43 * * *$ & - \\
\hline 7. & Moving intentions & $.19 * * *$ & $.23^{* * *}$ & $.10 * *$ & $-.07 *$ & $-.51 * * *$ & $.29 * * *$ \\
\hline
\end{tabular}

Note: $*: p<.05 ; * *: p<.01 ; * * *: p<.001$ 
Table 4. Standardized and Unstandardized Estimates ( $\mathrm{CI}_{95}$ in Brackets) of Regression Analyses in Study 2 Examining the Role of Perceived Norms in Neighborhood Satisfaction, Perceived Neighborhood Disadvantage, and Moving Intentions (Controlling for Individuallevel Background Characteristics and Objective Neighborhood-level Security and Crime Rates)

\begin{tabular}{|c|c|c|c|c|c|c|}
\hline & \multicolumn{2}{|c|}{$\begin{array}{l}\text { Neighborhood } \\
\text { Satisfaction }\end{array}$} & \multicolumn{2}{|c|}{$\begin{array}{l}\text { Neighborhood } \\
\text { Disadvantage }\end{array}$} & \multicolumn{2}{|c|}{$\begin{array}{l}\text { Moving } \\
\text { Intentions }\end{array}$} \\
\hline & $\beta$ & $\begin{array}{c}b \\
{\left[C I_{95}\right]}\end{array}$ & $\beta$ & $\begin{array}{c}b \\
{\left[C I_{95}\right]}\end{array}$ & $\beta$ & $\begin{array}{c}b \\
{\left[C I_{95}\right]}\end{array}$ \\
\hline $\begin{array}{l}\text { Perceived Diversity } \\
\text { (PD) }\end{array}$ & - $0.18 * * *$ & $\begin{array}{c}-0.15 \\
{[-0.20 ;-} \\
0.11]\end{array}$ & $0.37 * * *$ & $\begin{array}{c}0.28 \\
{[0.24 ;} \\
0.33]\end{array}$ & $0.13 * * *$ & $\begin{array}{c}0.11 \\
{[0.06 ;} \\
0.17]\end{array}$ \\
\hline $\begin{array}{l}\text { Perceived Norms } \\
(\mathrm{PN})\end{array}$ & $0.15^{* * * *}$ & $\begin{array}{c}0.18 \\
{[0.12 ;} \\
0.23]\end{array}$ & $0.12^{-} * * *$ & $\begin{array}{c}-0.14 \\
{[-0.20 ;-} \\
0.08]\end{array}$ & $-0.07 *$ & $\begin{array}{c}-0.08 \\
{[-0.14 ;-} \\
0.01]\end{array}$ \\
\hline PD X PN & $0.14 * * *$ & $\begin{array}{c}0.09 \\
{[0.06} \\
0.12]\end{array}$ & $0.10^{-} * * *$ & $\begin{array}{c}-0.06 \\
{[-0.09 ;-} \\
0.03]\end{array}$ & $-0.06 *$ & $\begin{array}{c}-0.04 \\
{[-0.07} \\
0.01]\end{array}$ \\
\hline $\begin{array}{l}\text { PD effect for low } \\
P N\end{array}$ & $0.32 * * *$ & $\begin{array}{c}-0.26 \\
{[-0.32 ;-} \\
0.21]\end{array}$ & $0.46 * * *$ & $\begin{array}{c}0.35 \\
{[0.30 ;} \\
0.41]\end{array}$ & $0.19 * * *$ & $\begin{array}{c}0.16 \\
{[0.09 ;} \\
0.22]\end{array}$ \\
\hline $\begin{array}{l}P D \text { effect for high } \\
P N\end{array}$ & -0.06 & $\begin{array}{c}-0.05 \\
{[-0.10} \\
0.01]\end{array}$ & $0.27 * * *$ & $\begin{array}{c}0.21 \\
{[0.15 ;} \\
0.27]\end{array}$ & $0.08 *$ & $\begin{array}{c}0.07 \\
{[0.00 ;} \\
0.14]\end{array}$ \\
\hline $\begin{array}{l}\text { Estimated Diversity } \\
\text { (ED) }\end{array}$ & $\begin{array}{c}- \\
0.23^{* * *}\end{array}$ & $\begin{array}{c}-1.66 \\
{[-2.07 ;-} \\
1.26]\end{array}$ & $0.39 * * *$ & $\begin{array}{c}2.64 \\
{[2.22 ;} \\
3.06]\end{array}$ & $0.15 * * *$ & $\begin{array}{c}1.11 \\
{[0.62 ;} \\
1.60]\end{array}$ \\
\hline $\begin{array}{l}\text { Perceived Norms } \\
\text { (PN) }\end{array}$ & $0.15 * * *$ & $\begin{array}{c}0.18 \\
{[0.13 ;} \\
0.24]\end{array}$ & $\stackrel{-}{-}$ & $\begin{array}{c}-0.14 \\
{[-0.20 ;-} \\
0.08]\end{array}$ & $-0.06^{*}$ & $\begin{array}{c}-0.07 \\
{[-0.14 ; 0 .-} \\
01]\end{array}$ \\
\hline ED X PN & $0.13 * * *$ & $\begin{array}{c}0.75 \\
{[0.45 ;} \\
1.04]\end{array}$ & $\stackrel{-}{-}$ & $\begin{array}{c}-0.50 \\
{[-0.80 ;-} \\
0.20]\end{array}$ & -0.04 & $\begin{array}{c}-0.27 \\
{[-0.62} \\
0.07]\end{array}$ \\
\hline $\begin{array}{l}\text { ED effect for low } \\
P N\end{array}$ & $\stackrel{-}{-}$ & $\begin{array}{c}-2.52 \\
{[-3.03 ;-} \\
2.02]\end{array}$ & $0.47 * * *$ & $\begin{array}{c}3.22 \\
{[2.70 ;} \\
3.74]\end{array}$ & $0.19 * * *$ & $\begin{array}{c}1.42 \\
{[0.82 ;} \\
2.02]\end{array}$ \\
\hline$\underset{P N}{\text { ED effect for high }}$ & $-0.11 * *$ & $\begin{array}{c}-0.81 \\
{[-1.36 ;-} \\
0.26]\end{array}$ & $0.30 * * *$ & $\begin{array}{r}2.07 \\
{[1.50 ;} \\
2.63]\end{array}$ & $0.11 *$ & $\begin{array}{c}0.80 \\
{[0.14 ;} \\
1.46]\end{array}$ \\
\hline $\begin{array}{l}\text { Objective Diversity } \\
\text { (OD) }\end{array}$ & $\begin{array}{c}- \\
0.13^{* * *}\end{array}$ & $\begin{array}{c}-1.50 \\
{[-2.25 ;-} \\
0.74]\end{array}$ & $0.23 * * *$ & $\begin{array}{c}2.47 \\
{[1.66 ;} \\
3.29]\end{array}$ & 0.05 & $\begin{array}{l}0.58 \\
{[-0.32 ;} \\
1.47]\end{array}$ \\
\hline $\begin{array}{l}\text { Perceived Norms } \\
(\mathrm{PN})\end{array}$ & $0.17 * * *$ & $\begin{array}{c}0.21 \\
{[0.15 ;} \\
0.27]\end{array}$ & $\stackrel{-}{-}$ & $\begin{array}{c}-0.17 \\
{[-0.24 ;-} \\
0.11]\end{array}$ & $-0.07 * *$ & $\begin{array}{c}-0.09 \\
{[-0.16 ;-} \\
0.02]\end{array}$ \\
\hline
\end{tabular}




\begin{tabular}{|c|c|c|c|c|c|c|}
\hline OD X PN & $0.15^{* * *}$ & $\begin{array}{c}1.55 \\
{[1.05 ;} \\
2.04]\end{array}$ & $-0.08 * *$ & $\begin{array}{c}-0.73 \\
{[-1.27 ;-} \\
0.20]\end{array}$ & -0.05 & $\begin{array}{c}-0.47 \\
{[-1.05 ;} \\
0.12]\end{array}$ \\
\hline OD effect for low & - & -3.28 & $0.31 * * *$ & 3.32 & $0.10^{a}$ & 1.11 \\
\hline$P N$ & $0.29 * * *$ & $\begin{array}{l}{[-4.26 ;-} \\
2.30]\end{array}$ & & $\begin{array}{l}{[2.26} \\
4.38]\end{array}$ & & $\begin{array}{c}{[-0.05 ;} \\
2.27]\end{array}$ \\
\hline $\begin{array}{l}\text { OD effect for high } \\
P N\end{array}$ & 0.03 & $\begin{array}{c}0.29 \\
{[-0.63} \\
1.20]\end{array}$ & $0.15 * * *$ & $\begin{array}{c}1.63 \\
{[0.65} \\
2.61]\end{array}$ & 0.00 & $\begin{array}{c}0.04 \\
{[-1.04 ;} \\
1.12]\end{array}$ \\
\hline
\end{tabular}

Note: ${ }^{a}: p=.06 ; *: p<.05 ; * *: p<.01 ; * * *: p<.001$ 


\section{Figures}

Figure 1. Conceptual Model of the Associations between Diversity, Neighborhood Norms and Moving Intentions via Neighborhood Satisfaction and Perceived Neighborhood Disadvantage

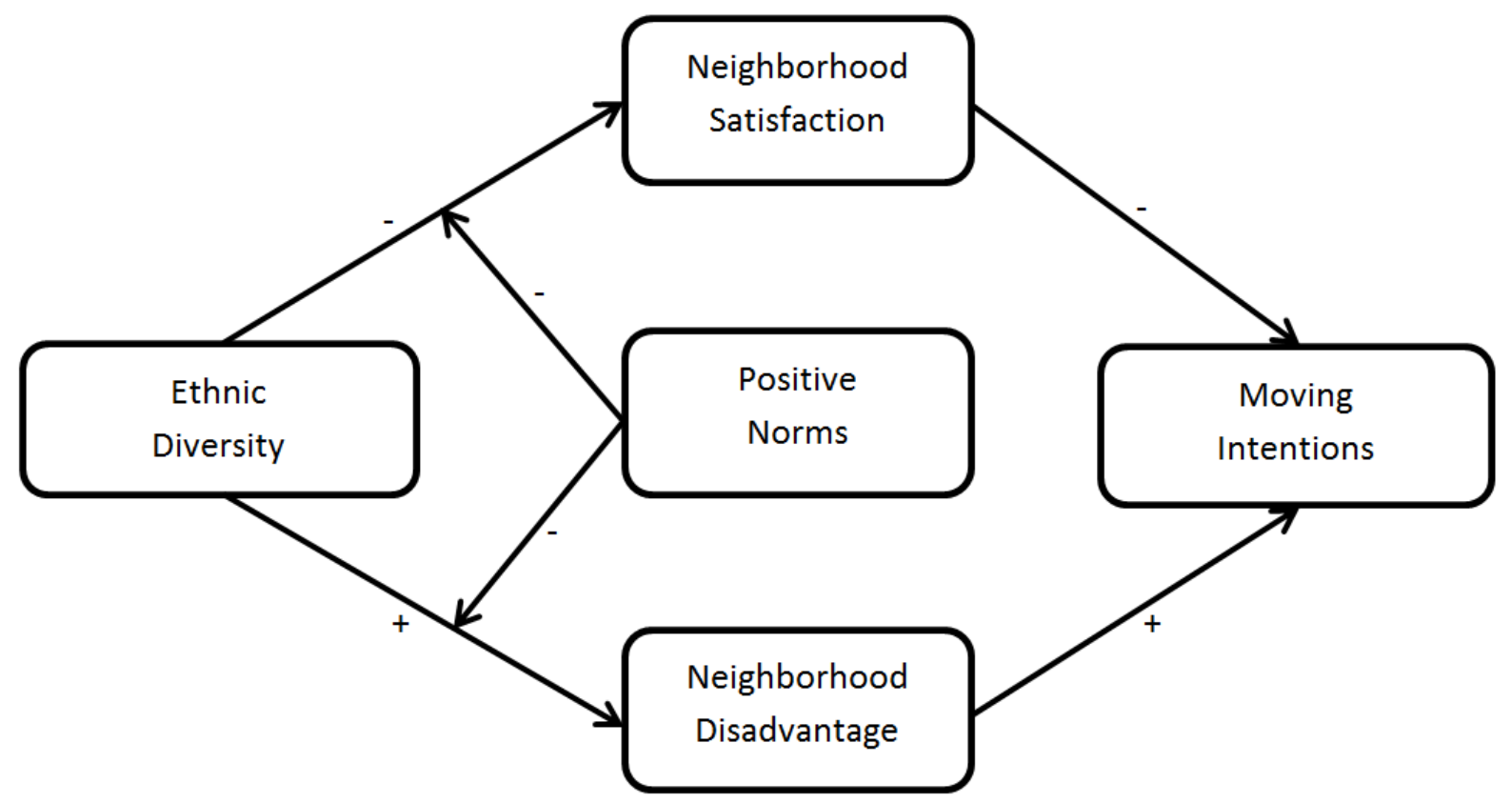


Figure 2. Standardized Results of the Model in Study 1 Testing the Association of Perceived Diversity with Moving Intentions via Neighborhood Satisfaction and Perceived Neighborhood Disadvantage, at High and Low Levels of Perceived Positive Neighborhood Norms (Controlling for Background Characteristics)

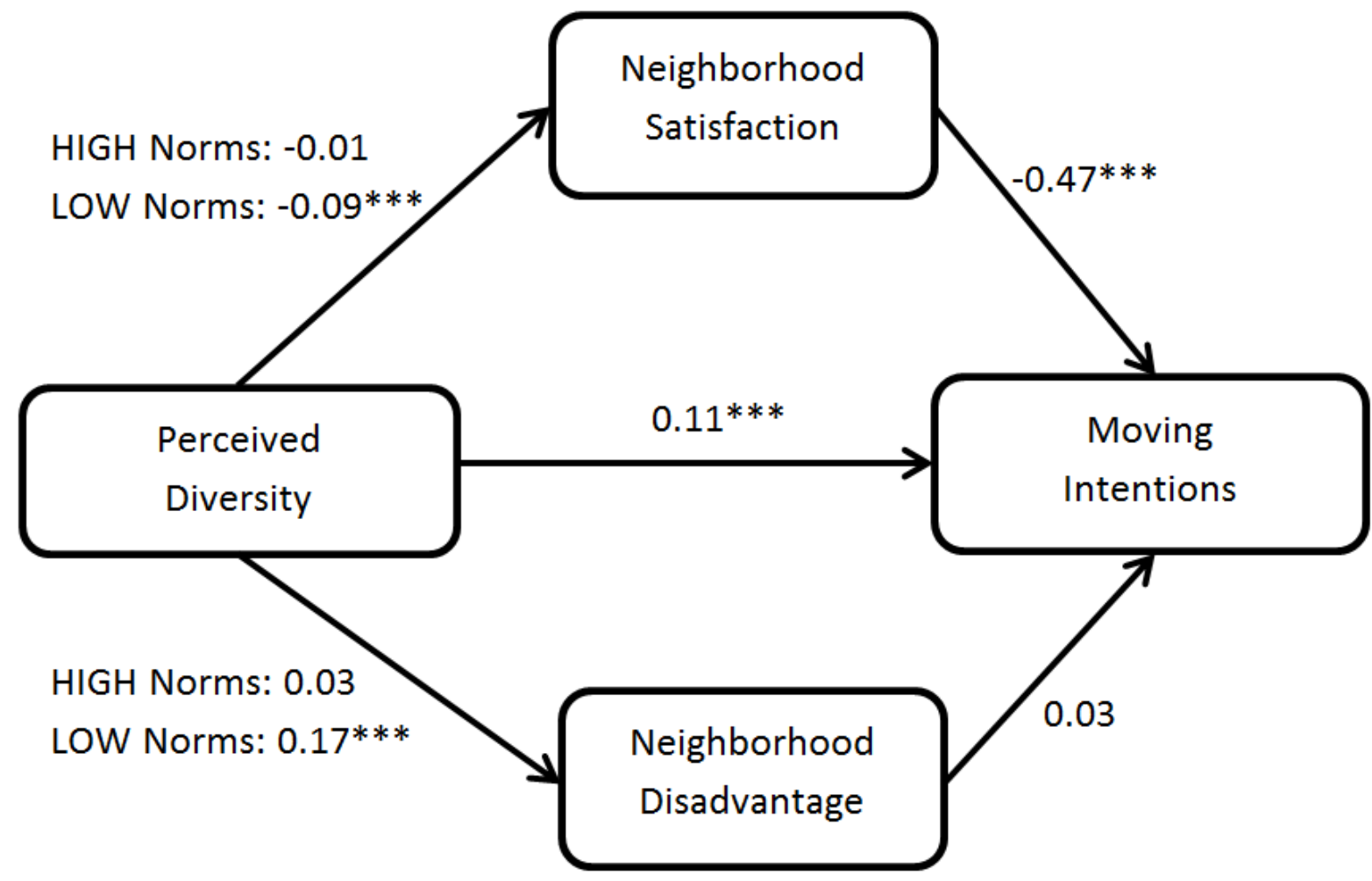

Note: $*: p<.05 ; * *: p<.01 ; * * *: p<.001$ 


\section{Figure 3}

Standardized results of the model in Study 2 testing the associations of perceived diversity (Figure 2a), estimated diversity (Figure 2b), and objective diversity (Figure 2c) with moving intentions via neighborhood satisfaction and perceived neighborhood disadvantage, at high and low levels of perceived positive neighborhood norms (controlling for background characteristics and objective neighborhood-level security and crime rates)

\section{Figure 3a}

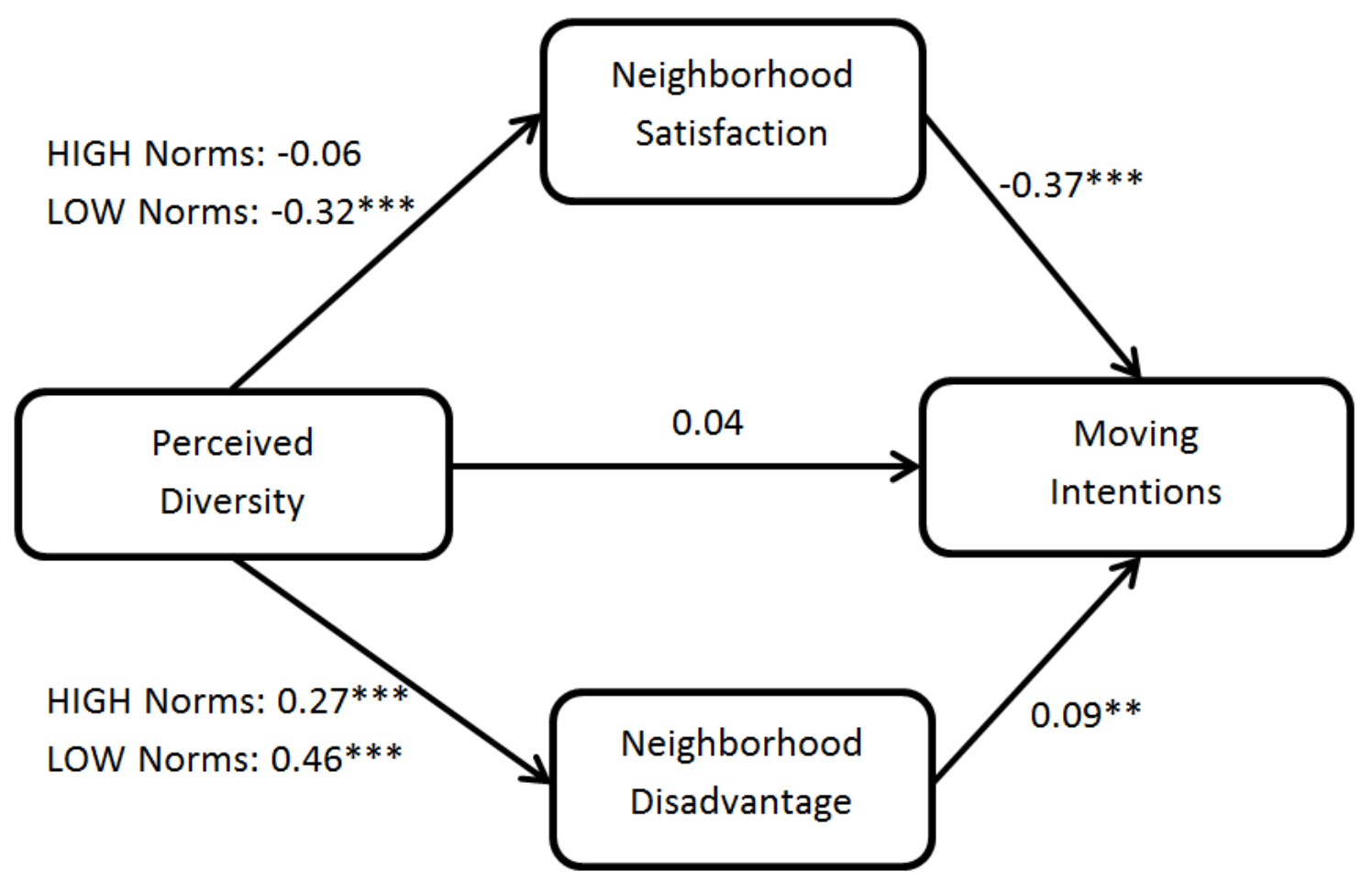


Figure 3b

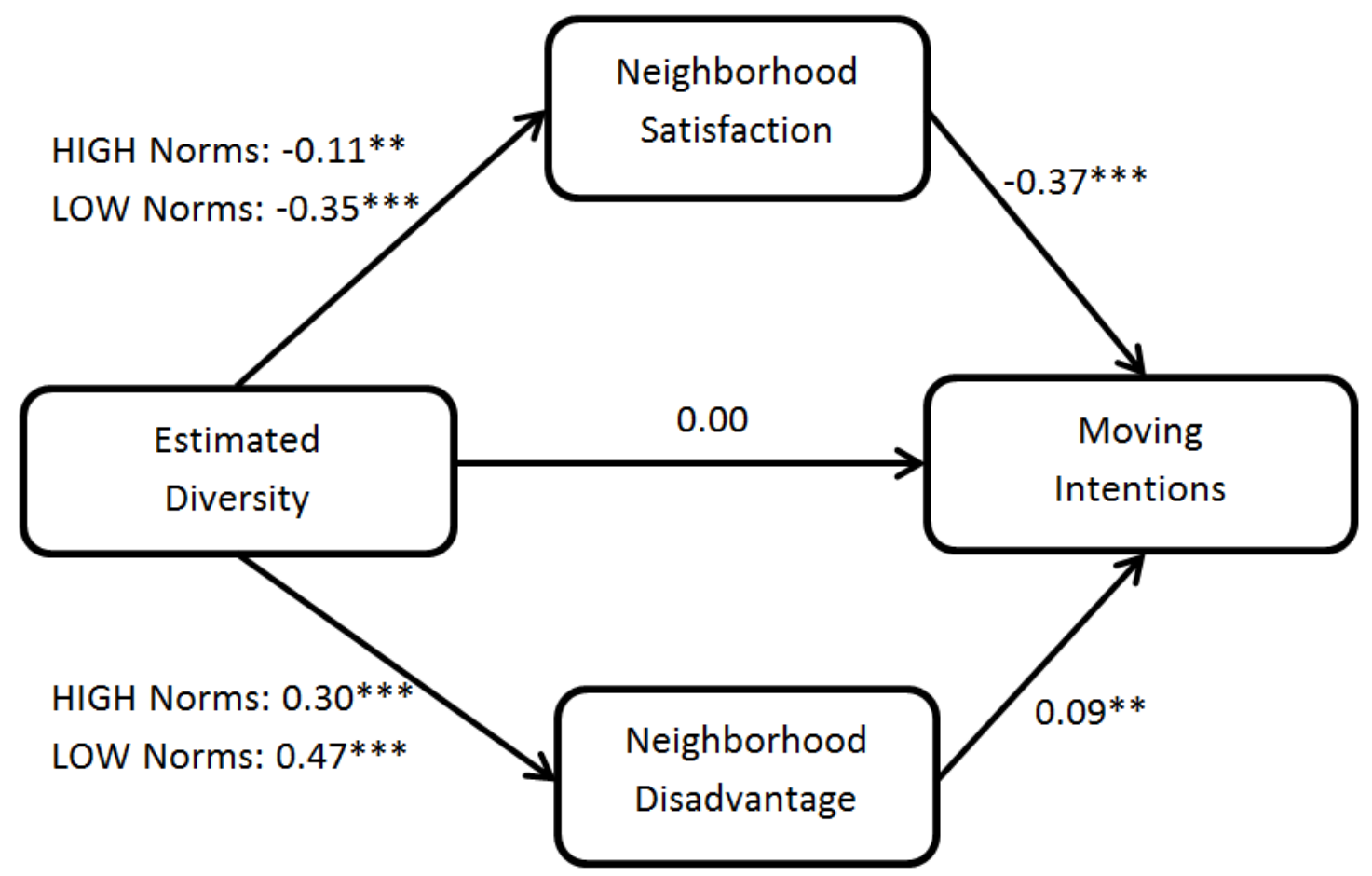

Figure 3c

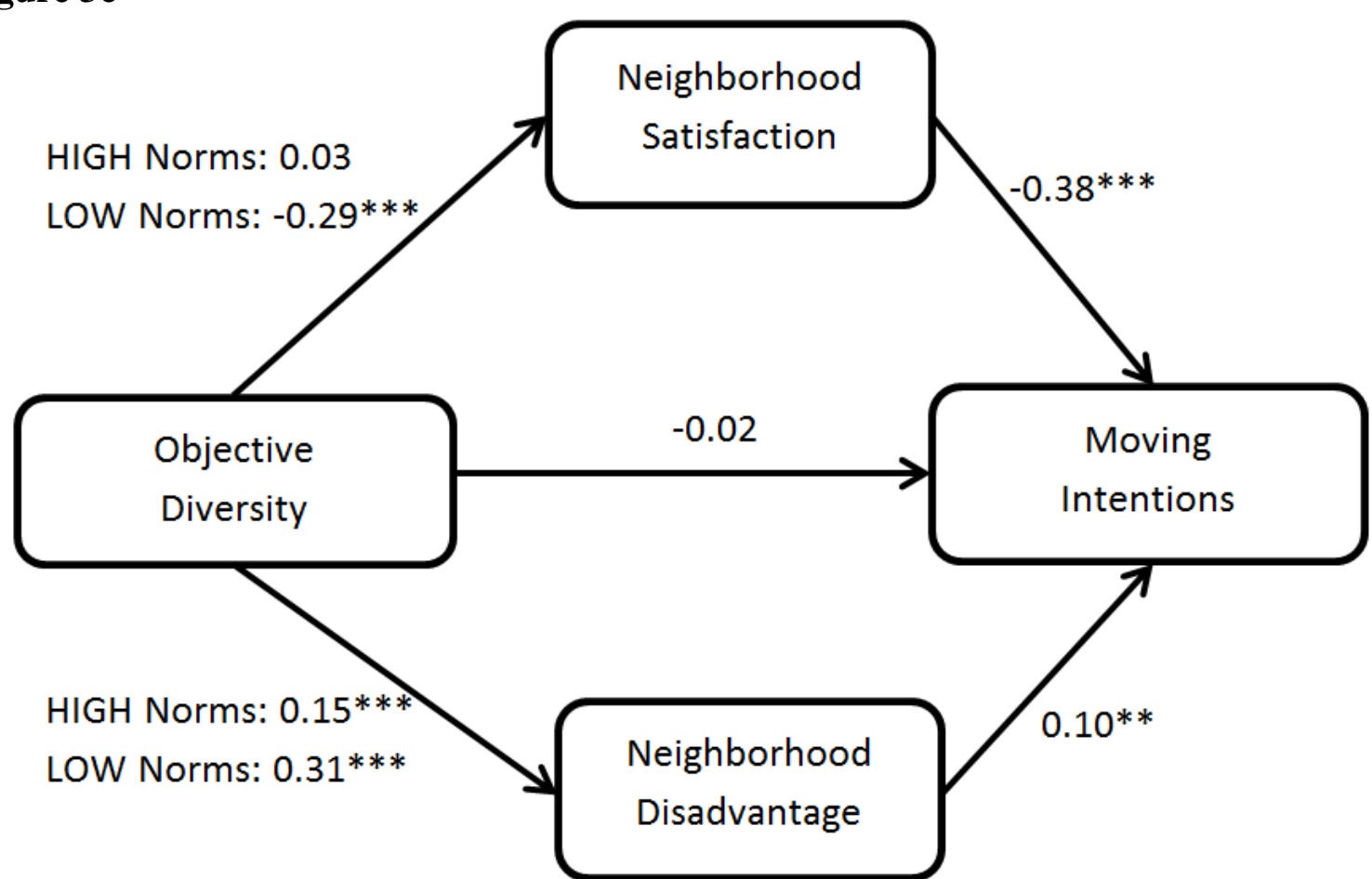

Note: $*: p<.05 ; * *: p<.01 ; * * *: p<.001$ 


\section{Appendix A: Income distributions per sample}

In Study 1, monthly net household income was fairly normally distributed, with 3\% earning less than $€ 500,10 \%$ between $€ 500$ and $€ 1,000,15 \%$ between $€ 1,000$ and $€ 1,500,18 \%$ between $€ 1,500$ and $€ 2,000,16 \%$ between $€ 2,000$ and $€ 2,500,10 \%$ between $€ 2500$ and $€ 3,000,8 \%$ between $€ 3000$ and $€ 3,500,5 \%$ between $€ 3,500$ and $€ 4,000,4 \%$ between $€ 4,000$ and $€ 4500,2 \%$ between $€ 4,500$ and $€ 5000$, and $4 \%$ earned more than $€ 5,000$. Four percent of the respondents chose not to divulge this information, and $1 \%$ did not know their income level. Sixty-eight percent of the sample was living in partnership and/or married, 31\% was single, and $1 \%$ chose not to disclose this information.

Finally, annual gross household income in Study 2 showed a fairly normal distribution, with $7 \%$ earning less than $€ 12,500,13 \%$ between $€ 12,500$ and $€ 26,000,25 \%$ between $€ 26,000$ and $€ 39,000,21 \%$ between $€ 39,000$ and $€ 65,000$, and $10 \%$ earned more than $€ 56,000$. Twenty-four percent of the respondents chose the option "I do not know / I do not want to disclose this information". 


\section{Appendix B: Additional analyses for personal intergroup norms (Study 2)}

Apart from perceptions of neighborhood intergroup norms, we also tapped into personal intergroup norms (see Christ et al., 2014). On a Likert scale ranging from 1 (totally disagree) to 7 (totally agree), respondents had to indicate to what extent they agreed with three statements (e.g., 'It is important for a neighborhood to have people of various ethnic backgrounds'). Cronbach's alpha of this scale was .86 , with $M=4.10(S D=1.35)$. As such, two items tapped into perceptions of positive neighborhood norms and three items tapped into personal intergroup norms (i.e., diversity beliefs). A principal component analysis with direct oblimin rotation including these five items yielded two components, with perceived and personal norms items having primary loadings on a different component (see Table A).

\section{Table A}

Pattern Matrix Coefficients among Norms Items in Study 2

Factor 1: $\quad$ Factor 2:

Item

In the neighborhood where I live, many people like to have contact with people of another ethnic group In the neighborhood where I live, there is an atmosphere in which immigrants and natives have the will to move forward together It is important for a neighborhood to have people of various ethnic backgrounds People of immigrant origin provide an enrichment of the cultural life in a neighborhood Bringing together different ethnic groups in a neighborhood is no problem for the social order

Perceived positive Positive personal intergroup norms intergroup norms
.95

.88

$-.07$

.01

.10
$-.04$

.06

.88

.81

Note: Secondary factor loadings in italics

Furthermore, personal intergroup norms were strongly positively related to perceived neighborhood norms $(r=.64, p<.001)$, and personal norms were also positively related to neighborhood satisfaction $(r=.21, p<.001)$, and negatively to perceived neighborhood disadvantage $(r=-.19, p<.001)$ and moving intentions $(r=-.11, p<.001)$. Interestingly, personal intergroup norms were unrelated to all facets of diversity. Table B and Figure A 
summarize the results of all analyses examining the buffering role of personal norms in diversity effects.

\section{Table B}

Standardized and unstandardized estimates (standard errors in brackets) of regression analyses in Study 2 examining the role of personal norms in neighborhood satisfaction, perceived neighborhood disadvantage, and moving intentions (controlling for background characteristics)

\begin{tabular}{|c|c|c|c|c|c|c|}
\hline & \multicolumn{2}{|c|}{$\begin{array}{l}\text { Neighborhood } \\
\text { Satisfaction }\end{array}$} & \multicolumn{2}{|c|}{$\begin{array}{l}\text { Neighborhood } \\
\text { Disadvantage }\end{array}$} & \multicolumn{2}{|c|}{$\begin{array}{c}\text { Moving } \\
\text { Intentions }\end{array}$} \\
\hline & $\beta$ & $\begin{array}{c}b \\
\text { (S.E.) }\end{array}$ & $\beta$ & $\begin{array}{c}b \\
\text { (S.E.) }\end{array}$ & $\beta$ & $\begin{array}{c}b \\
\text { (S.E.) }\end{array}$ \\
\hline Perceived Diversity (PD) & $-0.23 * * *$ & $\begin{array}{l}-0.19 \\
(0.02)\end{array}$ & $0.45 * * *$ & $\begin{array}{c}0.34 \\
(0.02)\end{array}$ & $0.14 * * *$ & $\begin{array}{c}0.12 \\
(0.02)\end{array}$ \\
\hline Personal Norms (PN) & $0.12 * * *$ & $\begin{array}{c}0.12 \\
(0.03)\end{array}$ & $-0.14 * * *$ & $\begin{array}{l}-0.14 \\
(0.03)\end{array}$ & $-0.07 *$ & $\begin{array}{l}-0.07 \\
(0.03)\end{array}$ \\
\hline PD X PN & $0.14 * * *$ & $\begin{array}{c}0.08 \\
(0.01)\end{array}$ & $-0.06 *$ & $\begin{array}{l}-0.03 \\
(0.01)\end{array}$ & $-0.06 *$ & $\begin{array}{l}-0.03 \\
(0.02)\end{array}$ \\
\hline PD effect for low PN & $-0.36 * * *$ & $\begin{array}{l}-0.29 \\
(0.03)\end{array}$ & $0.50 * * *$ & $\begin{array}{c}0.38 \\
(0.03)\end{array}$ & $0.20 * * *$ & $\begin{array}{c}0.16 \\
(0.03)\end{array}$ \\
\hline$P D$ effect for high $P N$ & $-0.11 * *$ & $\begin{array}{l}-0.09 \\
(0.03)\end{array}$ & $0.40 * * *$ & $\begin{array}{c}0.30 \\
(0.03)\end{array}$ & $0.09 *$ & $\begin{array}{c}0.07 \\
(0.03)\end{array}$ \\
\hline Estimated Diversity (ED) & $-0.26 * * *$ & $\begin{array}{l}-1.90 \\
(0.19)\end{array}$ & $0.46 * * *$ & $\begin{array}{c}3.16 \\
(0.20)\end{array}$ & $0.15 * * *$ & $\begin{array}{c}1.07 \\
(0.22)\end{array}$ \\
\hline Personal Norms (PN) & $0.12 * * *$ & $\begin{array}{c}0.13 \\
(0.03)\end{array}$ & $-0.12 * * *$ & $\begin{array}{l}-0.13 \\
(0.03)\end{array}$ & $-0.07 *$ & $\begin{array}{l}-0.07 \\
(0.03)\end{array}$ \\
\hline $\mathrm{ED} X \mathrm{PN}$ & $0.13 * * *$ & $\begin{array}{c}0.69 \\
(0.13)\end{array}$ & $-0.06 *$ & $\begin{array}{l}-0.29 \\
(0.13)\end{array}$ & $-0.07 *$ & $\begin{array}{l}-0.35 \\
(0.15)\end{array}$ \\
\hline ED effect for low $P N$ & $-0.39 * * *$ & $\begin{array}{l}-2.83 \\
(0.25)\end{array}$ & $0.52 * * *$ & $\begin{array}{c}3.55 \\
(0.26)\end{array}$ & $0.21 * * *$ & $\begin{array}{c}1.53 \\
(0.29)\end{array}$ \\
\hline ED effect for high PN & $-0.13 * * *$ & $\begin{array}{l}-0.98 \\
(0.26)\end{array}$ & $0.41 * * *$ & $\begin{array}{r}2.76 \\
(0.27) \\
\end{array}$ & $0.08 *$ & $\begin{array}{c}0.60 \\
(0.31)\end{array}$ \\
\hline Objective Diversity (OD) & $-0.18 * * *$ & $\begin{array}{l}-2.05 \\
(0.30)\end{array}$ & $0.33 * * *$ & $\begin{array}{c}3.58 \\
(0.32)\end{array}$ & $0.07 *$ & $\begin{array}{c}0.79 \\
(0.34)\end{array}$ \\
\hline Personal Norms (PN) & $0.14 * * *$ & $\begin{array}{c}0.14 \\
(0.03)\end{array}$ & $-0.15 * * *$ & $\begin{array}{l}-0.15 \\
(0.03)\end{array}$ & $-0.08 * *$ & $\begin{array}{l}-0.08 \\
(0.03)\end{array}$ \\
\hline OD X PN & $0.13 * * *$ & $\begin{array}{c}1.06 \\
(0.20)\end{array}$ & $-0.08 * *$ & $\begin{array}{l}-0.62 \\
(0.22)\end{array}$ & $-0.07 *$ & $\begin{array}{l}-0.56 \\
(0.24)\end{array}$ \\
\hline OD effect for low $P N$ & $-0.30 * * *$ & $\begin{array}{l}-3.47 \\
(0.43)\end{array}$ & $0.41 * * *$ & $\begin{array}{c}4.42 \\
(0.46)\end{array}$ & $0.12 * *$ & $\begin{array}{c}1.54 \\
(0.50)\end{array}$ \\
\hline OD effect for high $P N$ & -0.05 & $\begin{array}{l}-0.63 \\
(0.37)\end{array}$ & $0.26 * * *$ & $\begin{array}{c}2.74 \\
(0.40)\end{array}$ & 0.00 & $\begin{array}{c}0.04 \\
(0.43)\end{array}$ \\
\hline
\end{tabular}

Note: $*: p<.05 ; * *: p<.01 ; * * *: p<.001$

\section{Figure A}


Standardized results of the model in Study 2 testing the associations of perceived diversity (Figure A1), estimated diversity (Figure A2), and objective diversity (Figure A3) with moving intentions via neighborhood satisfaction and neighborhood disadvantage, at high and low levels of personal positive intergroup norms (controlling for background characteristics)

Figure A1

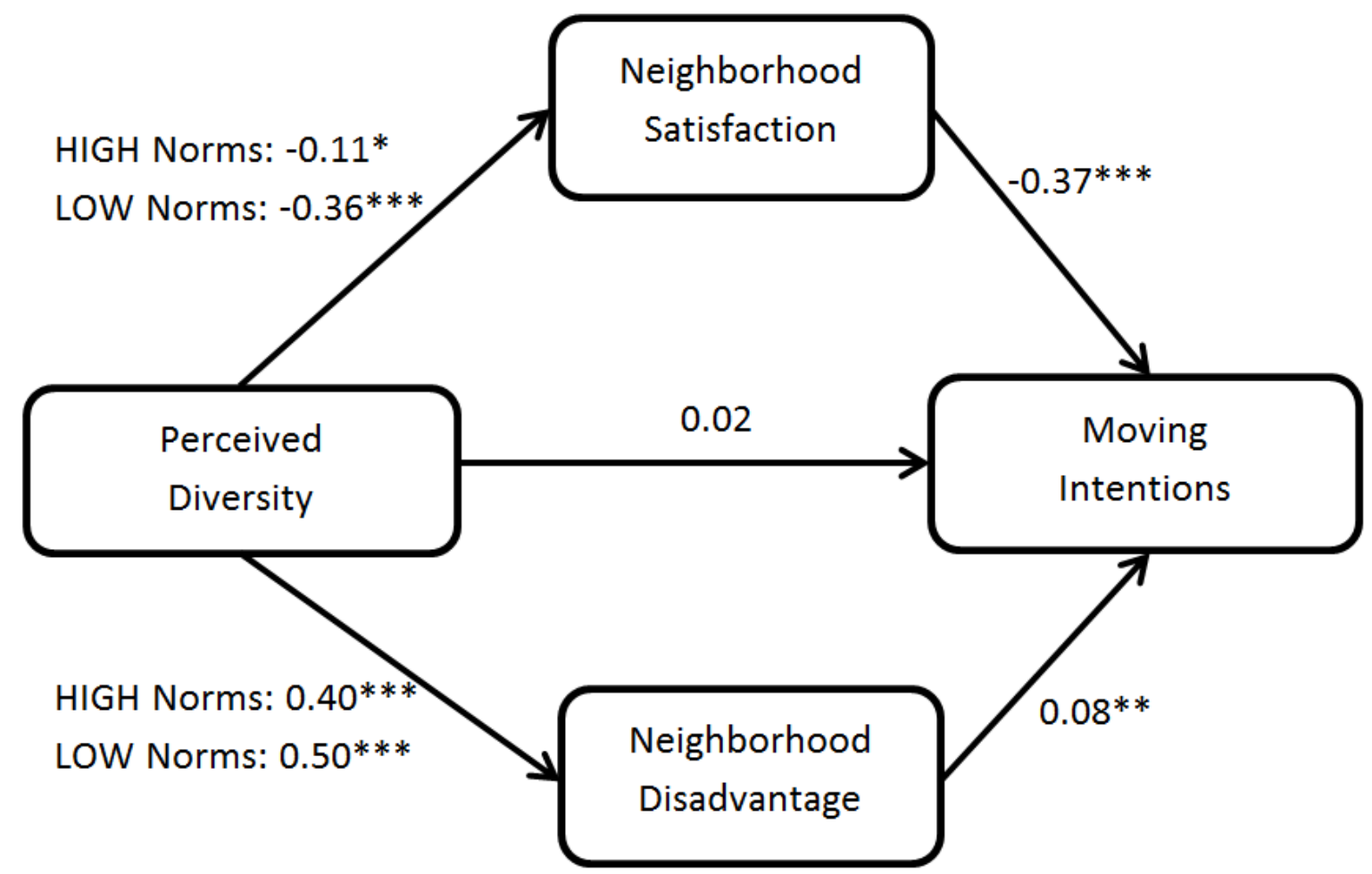

Figure A2

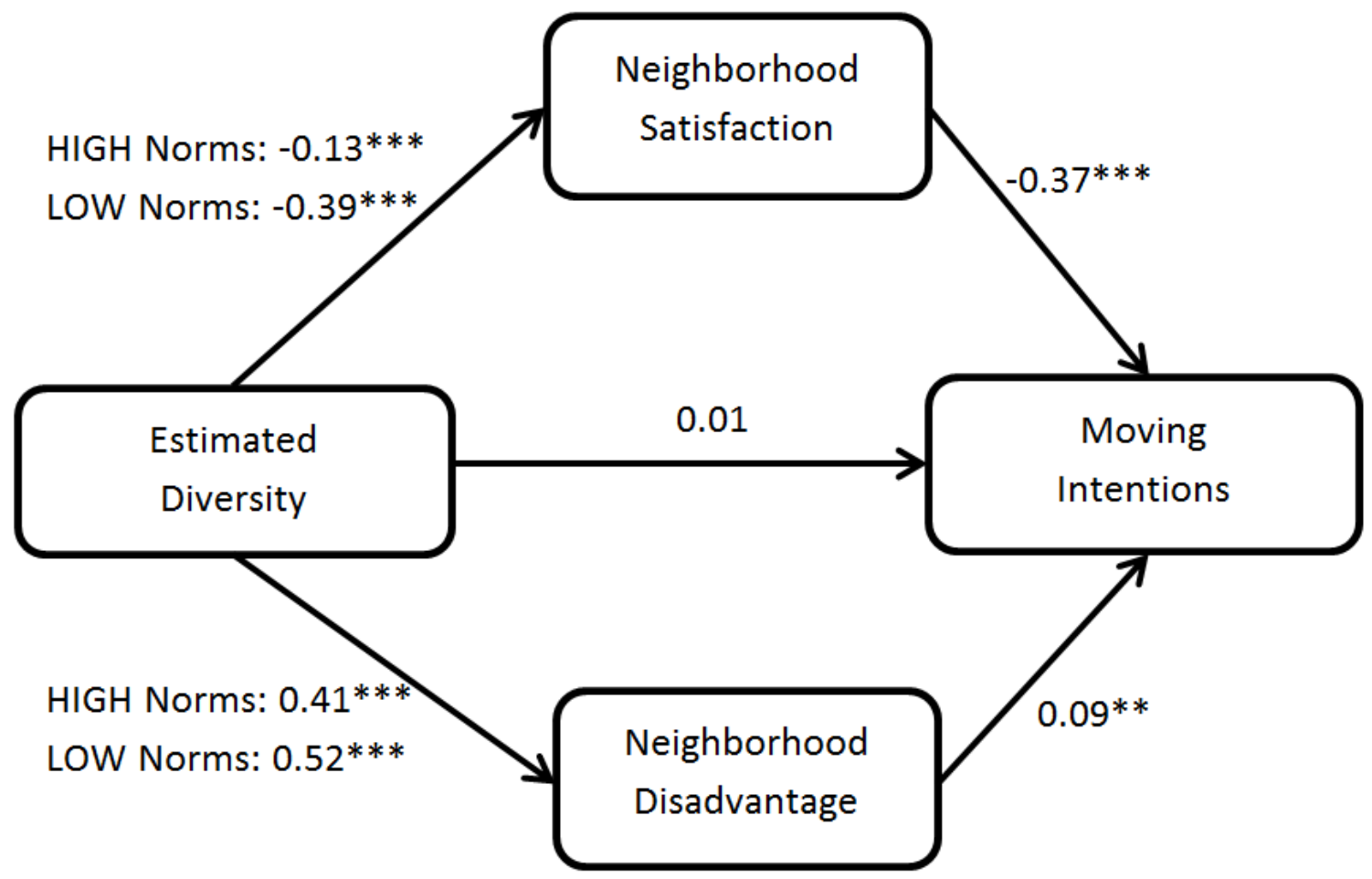

Figure A3 


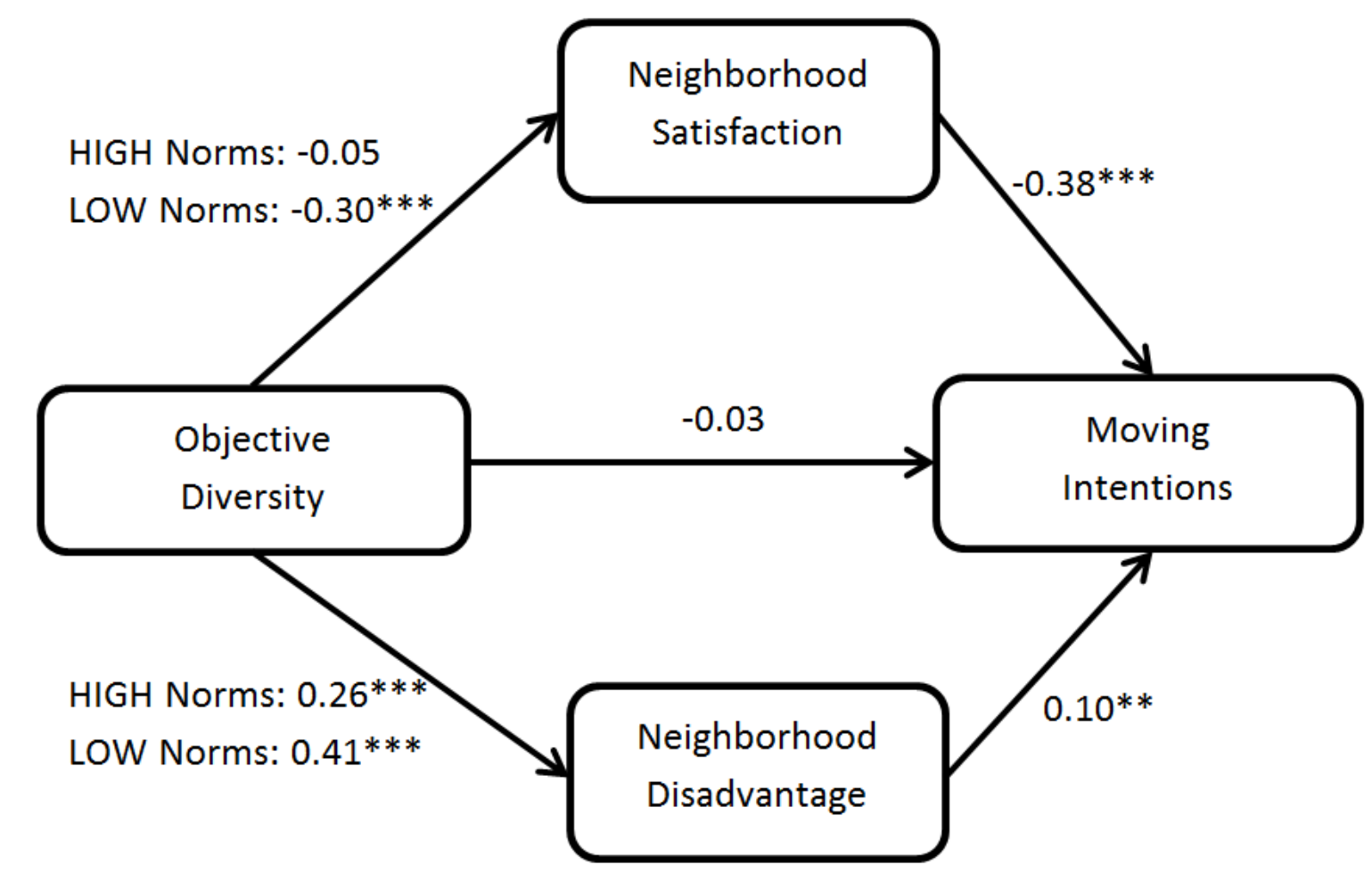

Note: $*: p<.05 ; * *: p<.01 ; * * *: p<.001$

Finally, the conditional indirect effects found with perceived intergroup norms were replicated for personal intergroup norms. Indeed, the indirect associations of higher diversity with higher moving intentions through lower neighborhood satisfaction were more pronounced among those holding less positive intergroup norms $(b=0.11 ;$ boot $S . E .=0.02 ; \beta$ $=0.13 ; p<.001$ for perceived diversity; $b=1.07$; boot $S . E .=0.17 ; \beta=0.14 ; p<.001$ for estimated diversity; and $b=1.32$; boot S.E. $=0.29 ; \beta=0.11 ; p<.001$ for objective diversity), as opposed to those holding strong positive intergroup norms $(b=0.03$; boot $S . E .=0.01 ; \beta=$ $0.04 ; p=.002$ for perceived diversity; $b=0.37$; boot $S . E .=0.12 ; \beta=0.05 ; p<.001$ for estimated diversity; and $b=0.24$; boot $S . E .=0.17 ; \beta=0.02 ; p=.10$ for objective diversity; see Figure 3a, 3b, and 3c, respectively). The indirect associations of higher diversity with higher moving intentions through higher perceived neighborhood disadvantage also tended to be stronger among people low $(b=0.03$; boot S.E. $=0.02 ; \beta=0.04 ; p=.01$ for perceived diversity; $b=0.33$; boot S.E. $=0.16 ; \beta=0.05 ; p=.009$ for estimated diversity; and $b=0.48$; 
boot S.E. $=0.20 ; \beta=0.04 ; p=.002$ for objective diversity) versus high in personal norms $(b=$ $0.03 ;$ boot $S . E .=0.01 ; \beta=0.03 ; p=.01$ for perceived diversity $b=0.26 ;$ boot $S . E .=0.13 ; \beta$ $=0.04 ; p=.01$ for estimated diversity; and $b=0.30 ;$ boot $S . E .=0.13 ; \beta=0.03 ; p=.003$ for objective diversity; see Figure A1, A2, and A3, respectively). 